\author{
锂硫电池先进功能隔膜的研究进展 \\ 黄佳琦 ${ }^{a, b}$ 孙漟智 ${ }^{b, c}$ 王云飞 ${ }^{b}$ 张强 ${ }^{*}, b$ \\ ( ${ }^{a}$ 北京理工大学前沿交叉科学研究院 材料学院 北京 100081) \\ ${ }^{b}$ 清华大学化学工程系 绿色反应工程与工艺北京市重点实验室＼cjkstart北京 100084) \\ (c 清华大学材料学院 北京 100084)
}

\begin{abstract}
摘要 随着电子设备和电动汽车对储能设备性能要求的不断提高, 锂硫电池因其多电子转化化学赋予的高能量密度受 到广泛关注. 当前锂硫电池的实用化受到库伦效率低、正极容量快速衰减、负极循环性能差等问题的制约. 针对锂硫 电池上述瓶领, 设计多功能电解质系统有望大幅提升活性材料的利用效率及循环寿命. 本文综述了近年来锂硫电池中 多功能隔膜系统的研究进展, 具体包括面向抑制副反应的选择性透过隔膜、面向正极的低界面电阻隔膜以及面向稳定 负极界面的隔膜. 并展望了锂硫电池多功能隔膜系统面临的科学挑战与未来发展的机遇.
\end{abstract}

关键词 锂硫电池; 隔膜; 电解质; 纳米碳; 复合材料; 金属锂

\title{
Review on Advanced Functional Separators for Lithium-Sulfur Batteries
}

Huang, Jiaqi ${ }^{a, b} \quad$ Sun, Yingzhi ${ }^{b, c} \quad$ Wang, Yunfei $^{b} \quad$ Zhang, Qiang*,b $^{*}$

( ${ }^{a}$ Advanced Research Institute for Multidisciplinary Science, School of Materials Science \& Engineering, Beijing Institute of Technology, Beijing 100081)

$\left({ }^{b}\right.$ Beijing Key Laboratory of Green Chemical Reaction Engineering and Technology, Department of Chemical Engineering, Tsinghua University, Beijing 100084)

( ${ }^{c}$ School of Materials Science and Engineering, Tsinghua University, Beijing 100084)

\begin{abstract}
As the demand to energy storage devices for portable electronics and electric vehicles increase, lithium-sulfur (Li-S) batteries have attracted much attention for its extremely high energy density. However, the low coulombic efficiency, rapid fading capacity, and poor cycle performance of lithium anode hinder the demonstration of practical Li-S cells. The advanced functional separator/interlayer system have been proposed and verified to retard the shuttle of polysulfides and extend the cycling life of a Li-S cell. In this review, the progress on multifunctional separators/interlayers for lithium sulfur batteries are summarized, including permselective separator inhibiting polysulfide shuttles, separator with low interfacial resistance, and composite electrolyte stabilizing anode and retarding the formation of Li dendrites. New insights into challenge and opportunities of multifunctional separator/interlayer system are also prospected.
\end{abstract}

Keywords lithium-sulfur batteries; separator/interlayer; electrolyte; nanocarbon; composite electrodes; Li anode

\section{1 引言}

以化石能源为基础的全球能源体系在能源枯竭和 环境污染方面日益令人担忧. 可再生的清洁能源技术以 及与之相适应的能源转换和储存系统是当代社会迫切 需求的新技术.

化学电池系统因其清洁、高效等特点在现代社会中 发挥着越来越重要的作用, 当然也面对着更高的使用要 求和技术挑战 ${ }^{[1,2]}$. 一方面, 车用化石燃料带来的污染是 城市环境恶化的重要源头. 为了采用清洁的化学电源取 代化石燃料, 必须使当下使用的化学电池系统能量密度 进一步提高, 以望克服其与化石燃料能量密度方面的巨 大差距(汽油能量密度约为 $44000 \mathrm{~kJ} \cdot \mathrm{kg}^{-1}$ ). 另一方面,
随着移动电子设备的小型化、轻量化, 其对新一代电池 提出了 “轻、薄、小” 的要求, 电池系统需具有更高的 能量密度. 因此, 开发环境友好、安全可靠、且具有更 高能量密度的电池系统是目前亟待解决的重要问题.

在众多的电池系统中, 铅酸电池、镍镉电池等普遍 存在较严重的环境污染问题且能量密度较低. 目前主流 的高能电池系统, 例如锂离子电池于 20 世纪 70 年代开 始产生原型. 随着社会发展, 锂离子电池的应用领域日 益广泛，渗透到人类生活的方方面面. 但是，受制于插 层反应化学所需电极材料仅能贡献较低的容量, 锂离子 电池比容量难以得到进一步提升 ${ }^{[3]}$. 发展下一代高性能 电池迫在眉睉 ${ }^{[4]}$.

在诸多下一代电池体系中, 锂硫电池系统具有相对

* E-mail: zhang-qiang@mails.tsinghua.edu.cn; zhangqiangflotu@tsinghua.edu.cn; Tel: 010-62789041

Received August 30, 2016; published November 10, 2016.

Project supported by the National Key Research and Development Program of China (No. 2016YFA0202500), Natural Scientific Foundation of China (Nos. 21306103 and 21422604), and Tsinghua University Initiative Scientific Research Program (No. 20161080166).

项目受国家重点研发计划(No. 2016YFA0202500)、国家自然科学基金(Nos. 21306103, 21422604)和清华大学自主科研计划(No. 20161080166)资助. 
较高的能量密度. 单质硫正极的理论比容量达到 1672 $\mathrm{mAh} \cdot \mathrm{g}^{-1}$ ，与金属锂组成电池时电池对的理论能量密度 可达 $2600 \mathrm{Wh} \cdot \mathrm{kg}^{-1}$. 该数值为锂离子电池理论能量密度 的 $3 \sim 5$ 倍 ${ }^{[5,6]}$, 从而赋予其作为下一代高能量密度电池 系统的可能性.

\section{2 锂硫电池系统}

典型的锂硫电池系统是由金属锂作为负极, 硫作为 正极构成的储能系统. 其中, 硫原料廉价、易得且相对 环保的特点是锂硫电池的巨大优势 ${ }^{[7 \sim 10]}$. 典型的单质硫 与锂离子在电化学过程中主要发生如下反应:

$$
\begin{aligned}
& \mathrm{S}_{8} \text { (固体) }+2 \mathrm{Li}^{+}+2 \mathrm{e}^{-} \longleftrightarrow \mathrm{Li}_{2} \mathrm{~S}_{8} \text { (可溶) } \\
& 3 \mathrm{Li}_{2} \mathrm{~S}_{8} \text { (可溶) }+2 \mathrm{Li}^{+}+2 \mathrm{e}^{-} \longleftrightarrow 4 \mathrm{Li}_{2} \mathrm{~S}_{6} \text { (可溶) } \\
& 2 \mathrm{Li}_{2} \mathrm{~S}_{6} \text { (可溶) }+2 \mathrm{Li}^{+}+2 \mathrm{e}^{-} \longleftrightarrow 3 \mathrm{Li}_{2} \mathrm{~S}_{4} \text { (可溶) } \\
& \mathrm{Li}_{2} \mathrm{~S}_{4} \text { (可溶) }+2 \mathrm{Li}^{+}+2 \mathrm{e}^{-} \longleftrightarrow 2 \mathrm{Li}_{2} \mathrm{~S}_{2} \text { (固体) } \\
& \mathrm{Li}_{2} \mathrm{~S}_{2} \text { (固体) }+2 \mathrm{Li}^{+}+2 \mathrm{e}^{-} \longleftrightarrow \longrightarrow 2 \mathrm{Li}_{2} \mathrm{~S} \text { (固体) }
\end{aligned}
$$

锂硫电池电化学反应过程与锂离子电池存在显著 差别. 活性物质 $\mathrm{S}_{8}$ 分子发生可逆的多电子氧化还原反 应. 在第一阶段反应中, $\mathrm{S}_{8}$ 分子主要被还原为可溶多硫 化物分子 $\mathrm{S}_{x}{ }^{2-}(8 \geqslant x \geqslant 4)$, 电位约为 $2.4 \mathrm{~V} \mathrm{vs.} \mathrm{Li} / \mathrm{Li}^{+}$; 第 二阶段反应中, 多硫化物分子被进一步还原为不溶的放 电最终产物 $\mathrm{Li}_{2} \mathrm{~S}_{2}$ 及 $\mathrm{Li}_{2} \mathrm{~S}$, 电位约为 $2.1 \mathrm{~V}$ vs. $\mathrm{Li} / \mathrm{Li}^{+}$. 相 对传统锂离子电池, 硫分子的多电子反应本征特性带来 了电极材料的高容量特点, 但同时导致锂硫电池系统存 在更多的复杂性, 主要体现在以下几个方面 ${ }^{[5,11 ~ 14]}$ :

(1)单质硫及放电产物硫化锂的电导率低, 均为电 子及离子绝缘体, 单质硫在室温下电导率仅为 $5 \times 10^{-30}$ $\mathrm{S} \cdot \mathrm{cm}^{-1}$.

(2)硫在充电态(单质硫)和放电态(硫化锂)之间存在 巨大体积变化. 单质硫密度为 $2.03 \mathrm{~g} \cdot \mathrm{cm}^{-3}$, 在放电过程 中转变为密度较低的硫化锂(密度 $1.67 \mathrm{~g} \cdot \mathrm{cm}^{-3}$ ), 体积膨 胀; 在充电的过程中逆向反应体积减小. 体积的变化易 导致电极导电结构的破坏并使电池性能迅速衰减.

(3)硫电极在充放电过程中产生可溶的多硫化物, 一方面导致高阶多硫化物跨隔膜扩散与金属锂负极直 接反应生成低阶多硫化物, 带来锂硫电池中的副反应循 环，也即 “穿梭效应”，降低锂硫电池的库伦效率; 另 一方面也导致含硫组分在电池中的损失, 使电池性能发 生快速衰减.

(4)金属锂负极表面固体电解质界面膜稳定性不足, 在循环的过程中循环效率低, 易粉化; 同时存在锂负极 枝晶生长等问题, 影响电池的安全性.

受锂硫电池系统如上特点影响, 锂硫电池活性材料 利用率偏低, 电池循环性能不佳, 尽管在 20 世纪 70 年 代就提出这种可行的电池体系, 但是长期以来锂硫电池 并未受到科学界的关注. 2002 年, 上海交通大学王久林 等 ${ }^{[15]}$ 首次提出采用聚丙烯腈与硫复合的方式，获得了
高性能的锂硫电池正极材料. 2008 年, 加拿大 Nazar 组 ${ }^{[16]}$ 发展了使用介孔碳作为硫载体发展硫正极的方法, 进一步提高了锂硫电池正极的性能. 这些先驱性的工作 唤起了人们对锂硫电池作为下一代高比能储能电池的 兴趣. 此后, 纳米材料也被引入到锂硫电池的正极材料 当中, 尤其是导电碳材料 ${ }^{[17 \sim 22]}$ 、极性导电骨架 ${ }^{[23 \sim 27]}$ 以及 电催化剂 ${ }^{[28,29]}$ 的开发带来了锂硫电池正极材料的极大 发展. 同时，硫的共价化学固定方法也获得了一系列高 性能的硫-高分子复合正极材料 ${ }^{[30]}$ 、硫-硒杂环复合正 极 ${ }^{[31]}$. 随着研究的深入, 通过在硫电极系统中提高电子 及离子的传递效率，基本解决了硫材料低电导率和体积 形变方面的难题，实现了在正极材料中活性材料硫的高 效利用 ${ }^{[32 \sim 37]}$.

针对锂硫电池中负极性能的提升主要集中在金属 锂负极本身的纳米化 ${ }^{[38]}$ 以及电解液 ${ }^{[39,40]}$ 调控两个方面. 通过负极的纳米化过程 ${ }^{[41 ~ 43]}$, 可以有效提升负极的循 环稳定性. 通过降低金属理负极面电流密度可以有效抑 制枝晶的生长 ${ }^{[44,45]}$, 获得高安全的金属锂负极. 另一方 面, 从电解液角度入手, 改变电解液的溶剂, 或提高电 解液中盐浓度均可以部分抑制多硫化物的扩散，从而提 高锂硫电池的循环稳定性 ${ }^{[46]}$; 如果直接在电解液中添 加合适比例的多硫化物, 有望维持循环过程中多硫化物 浓度的相对稳定，以提高负极的循环效率 ${ }^{[47,48]}$.

锂硫电池器件的性能不仅仅取决于正极、负极活性 材料的结构和性能, 还取决于正负极之间的电解质体 系. 隔膜组件是正负极材料之间的典型电解质 ${ }^{[49]}$. 锂硫 电池中多功能隔膜的开发有望克服锂硫电池研究目前 遇到的众多困难，获得有实用价值的锂硫电池.

\section{3 锂硫电池多功能隔膜系统}

隔膜系统是电池中的核心组件之一. 在常规的锂离 子电池中，隔膜的作用是防止电池正极、负极直接接触 发生电子短路; 同时通过隔膜中的孔道保持正负极两侧 的电解液联通, 维持正负极之间的离子通道 ${ }^{[50,51]}$. 在锂 硫电池系统中，因其多电子反应的特性，隔膜在避免正 负极短路、维持正负极之间离子通道之外，可通过多功 能化发挥更大的作用, 提升锂硫电池性能, 主要体现在:

(1)通过抑制多硫化物的跨膜扩散，阻止 “穿梭效 应”的发生, 提升锂硫电池的库伦效率.

(2)通过改善正极隔膜界面的设计, 降低正极侧界 面电阻，同时实现含硫组分的回收利用，大幅提升锂硫 电池的循环稳定性.

(3)通过改善负极隔膜界面的设计，稳定金属锂负 极表面结构，获得具有更高循环稳定性或抑制枝晶生长 的高安全金属锂负极.

本文将针对锂硫电池中多功能隔膜的这三个主要 功能开展评述. 


\section{1 抑制多硫化物扩散的多功能隔膜}

锂硫电池中多硫化物的跨膜扩散及其导致的相应 副反应是电池性能劣化的重要原因 ${ }^{[52]}$. 通过多功能隔 膜的设计可以实现对多硫化物跨膜扩散的抑制，从而提 升锂硫电池库伦效率等性能. 在实际锂硫电池系统中, 器件要求抑制多硫化物阴离子扩散, 同时维持锂离子的 跨膜输运, 从而对隔膜提出离子选择性透过的要求. 利 用多硫化物阴离子和锂离子在荷电属性、动力学直径以 及化学吸附行为方面的差异, 获得通过静电排斥效应, 空间位阻效应，以及可控化学吸附三种手段实现抑制多 硫化物扩散的多功能隔膜电解质材料.

\section{1 .1 通过电荷排斥效应抑制多硫化物扩散}

利用多硫化物阴离子和锂离子的荷电属性差异, 通 过电荷排斥效应即可实现多硫化物阴离子的扩散. 国防 科技大学 Jin 等 ${ }^{[53]}$ 首先提出采用锂化的 Nafion 膜来抑制 锂硫电池中副反应的发生, 该工作中锂离子的迁移数可 达到 0.986 , 证实在电池中的离子传递基本由锂离子提 供, 进而有效抑制多硫化物阴离子的跨膜扩散. Yu 等 ${ }^{[54]}$ 利用商业化的无孔 Nafion 膜作为锂硫电池中阳离子选 择性透过膜, 采用预锂化的方法显著提升 Nafion 膜中锂 离子迁移能力, 验证了在锂硫电池中阻挡多硫化物的作 用, 进而提升电池的循环稳定性.

为进一步降低离子选择性隔膜对锂离子迁移的阻 力, 本课题组提出了离子选择性多功能锂硫电池隔膜的 设计策略. 以 Nafion 为功能层, 在隔膜表面实现超薄功 能层负载, 在低负载量 $\left(0.7 \mathrm{mg} \bullet \mathrm{cm}^{-2}\right)$ 下同时实现了保留 锂离子输运通道和阻止多硫化物阴离子扩散的功能. 在 该离子选择性隔膜中, 磺酸根可以提供锂离子跃迁位 点, 实现锂离子的输运; 磺酸根提供电荷排斥作用阻止 多硫化物聚硫阴离子透过. 通过引入该离子选择性隔 膜, 可在采用无硝酸锂电解液的情况下, 将锂硫电池库 伦效率提高至 $95 \%$ 以上, 500 个充放电循环后保持 $60 \%$ 以上的初始容量 ${ }^{[55}$. 利用这一策略, 也可以有效抑制锂 硫电池中多硫化物扩散反应带来的显著自放电现象 ${ }^{[56]}$. 随后，德国 Bauer 等 ${ }^{[57]}$ 也报道了利用锂化的 Nafion 修饰 隔膜的策略来抑制迁移效应. Nafion 隔膜体系在常温的 钠硫电池等体系中也可得到应用, 通过类似的机理抑制 多硫阴离子扩散带来的副反应 ${ }^{[58,59]}$.

利用 Nafion 的离子选择性透过特征构建复合体系 在阻隔多硫化物方面也具有显著优势 ${ }^{[60]}$. 隔膜修饰层 过厚则不利于电池中的离子传输, 难以使电池体系获得 高能量密度. 为获得更高效的离子选择性隔膜, 本课题 组进一步提出协同复合的思路, 提出三层膜策略. 采用 超薄的氧化石墨烯薄层封闭 Celgard 隔膜上的大孔, 然 后利用全氟磺酸树脂 Nafion 修饰在氧化石墨烯上, 加强 对多硫化物的电荷排斥功能. 该结构可使功能层在负载 量仅为 $0.053 \mathrm{mg} \cdot \mathrm{cm}^{-2}$, 厚度仅为 $100 \mathrm{~nm}$ 的情况下, 有 效抑制多硫化物的跨膜扩散, 抑制穿梭效应. 采用该隔
膜组装锂硫电池，在不含硝酸锂添加剂的情况下可将库 伦效率从 $80 \%$ 提升至 $95 \%$ 以上; 与硫负载量高达 4.0 $\mathrm{mg} \cdot \mathrm{cm}^{-2}$ 的正极配合使用时仍能实现 $73 \%$ 硫利用率及优 异的倍率特性 ${ }^{[61]}$. 华中科技大学黄云辉课题组 ${ }^{[62]}$ 采用 Nafion 与 SuperP 导电炭黑复合修饰隔膜, 获得双功能隔 膜系统. 其中 Nafion 层可抑制多硫化物阴离子的扩散, 而 SuperP 颗粒可实现部分物理阻挡, 有效提升功能层 阻挡效率. 浙江大学李洲鹏课题组 ${ }^{[63]}$ 也报道 NafionSuperP-PEO 混合功能层用以抑制多硫化物的跨膜扩散.

除 Nafion 外, 其他具有静电排斥能力的高分子也被 用于多功能隔膜中. 例如, Jin 等 ${ }^{[64]}$ 采用 Li-PFSD 结构 (lithium perfluorinated sulfonyl dicyanomethide), 利用 $\left(-\mathrm{SO}_{2} \mathrm{C}(\mathrm{CN})_{2} \mathrm{Li}\right)$ 基团作为锂离子选择性迁移基团实现锂 离子的选择性透过. 由于 Li-PFSD 具有更佳的锂离子透 过能力, 其在大电流充放电情况下的性能较预锂化的 Nafion 具有优势, 使电池具有较高的倍率性能. $\mathrm{Gu}$ 等 ${ }^{[65]}$ 利用 PAH [poly(allylamine hydrochloride)] 和 PAA [poly(acrylic acid)]在聚乙烯隔膜表面的层层自组装获得 离子选择性隔膜. 通过控制组装过程的 $\mathrm{pH}$ 值以及两类 荷电材料的组装比例, 可以精确调控功能层内部的荷电 量, 通过增加带负电的自由羧酸基团的量, 实现锂离子 的选择性透过. 采用此隔膜可获得接近 $100 \%$ 的锂硫电 池库伦效率, 并取得 $1418 \mathrm{mAh} \cdot \mathrm{g}^{-1}$ 的初始可逆循环容 量. Conder 等 ${ }^{[66,67]}$ 利用等离子体活化的方式, 在多孔聚 丙烯隔膜表面修饰聚苯乙烯磺酸基团(styrene sulfonate), 利用其体现的荷电性质可以有效限制多硫化物的扩散, 提升锂硫电池的库伦效率.

防化研究院王安邦, 王维坤课题组 ${ }^{[68]}$ 在乙炔黑表 面引入磺酸基团, 获得磺化乙炔黑材料. 进一步采用磺 化乙炔黑修饰隔膜, 可在隔膜表面形成负载量为 0.13 $\mathrm{mg} \cdot \mathrm{cm}^{-2}$, 厚度约为 $6 \mu \mathrm{m}$ 的功能层. 该功能层内存在大 量磺酸根基团，可通过静电荷排斥的效应有效阻隔多硫 化物的跨膜扩散，另一方面炭黑层仍保留较好的导电 性，可促进正极表面的电荷转移.

采用部分荷电的无机材料，也可以实现对多硫化物 阴离子扩散的有效抑制. 例如，亲水的蒙脱土涂层可以 提升隔膜在电解液中的润湿性能, 并且可以通过静电排 质等作用防止多硫化物透过隔膜与负极发生反应. Ahn 等 ${ }^{[69]}$ 利用蒙脱土修饰的多功能隔膜, 在锂硫电池中获 得了 $0.16 \%$ 的单圈容量衰减率以及高达 $1382 \mathrm{mAh} \cdot \mathrm{g}^{-1}$ 的首圈放电容量. 近期, $\mathrm{Kim}$ 等 ${ }^{[70]}$ 采用 $\mathrm{BaTiO}_{3}$ 颗粒修饰 聚乙烯隔膜, 通过极化的过程使 $\mathrm{BaTiO}_{3}$ 颗粒沿电场方 向定向，并在多功能隔膜中形成定向电场，实现对多硫 化物的电荷排斥，大幅提升了电池的稳定性.

\subsection{2 通过空间位阻效应抑制多硫化物扩散}

利用多硫化物阴离子与锂离子在动力学直径方面 的差异, 通过隔膜中孔道的设计实现锂离子的选择性透 过，从而抑制锂硫电池中的 “穿梭效应”. 
(a)

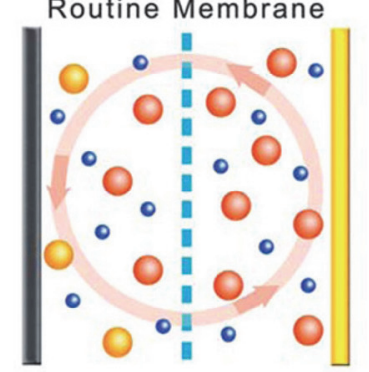

High/low order polysulfides

a Sulfur electrode

(b)

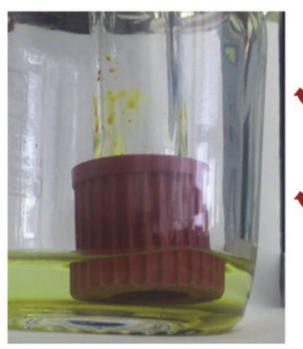

(d)
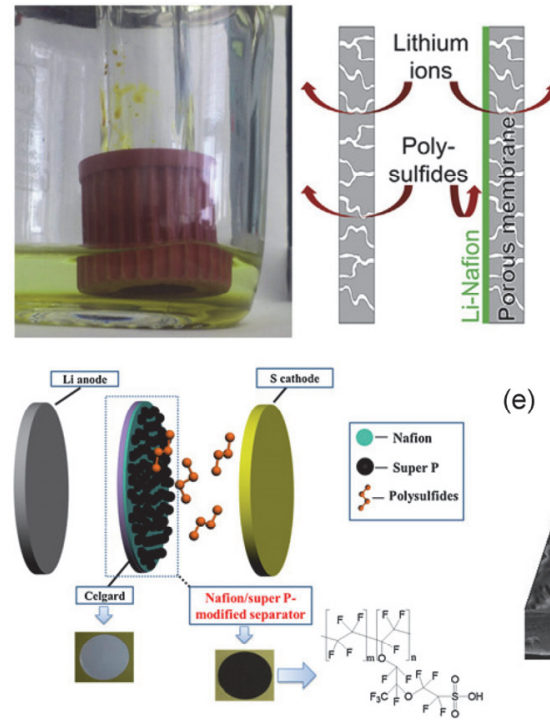

(e)

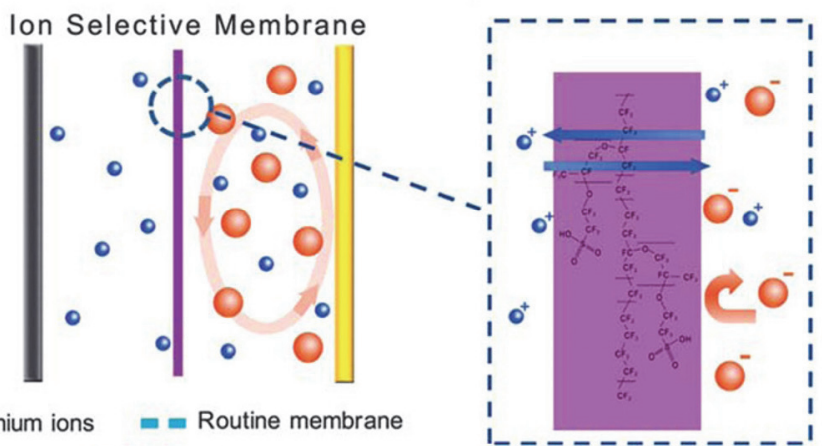

(f)

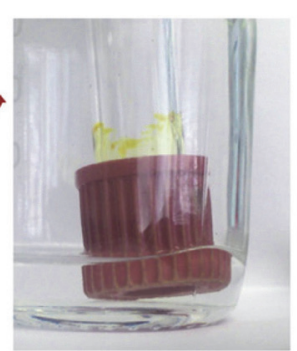

(c)
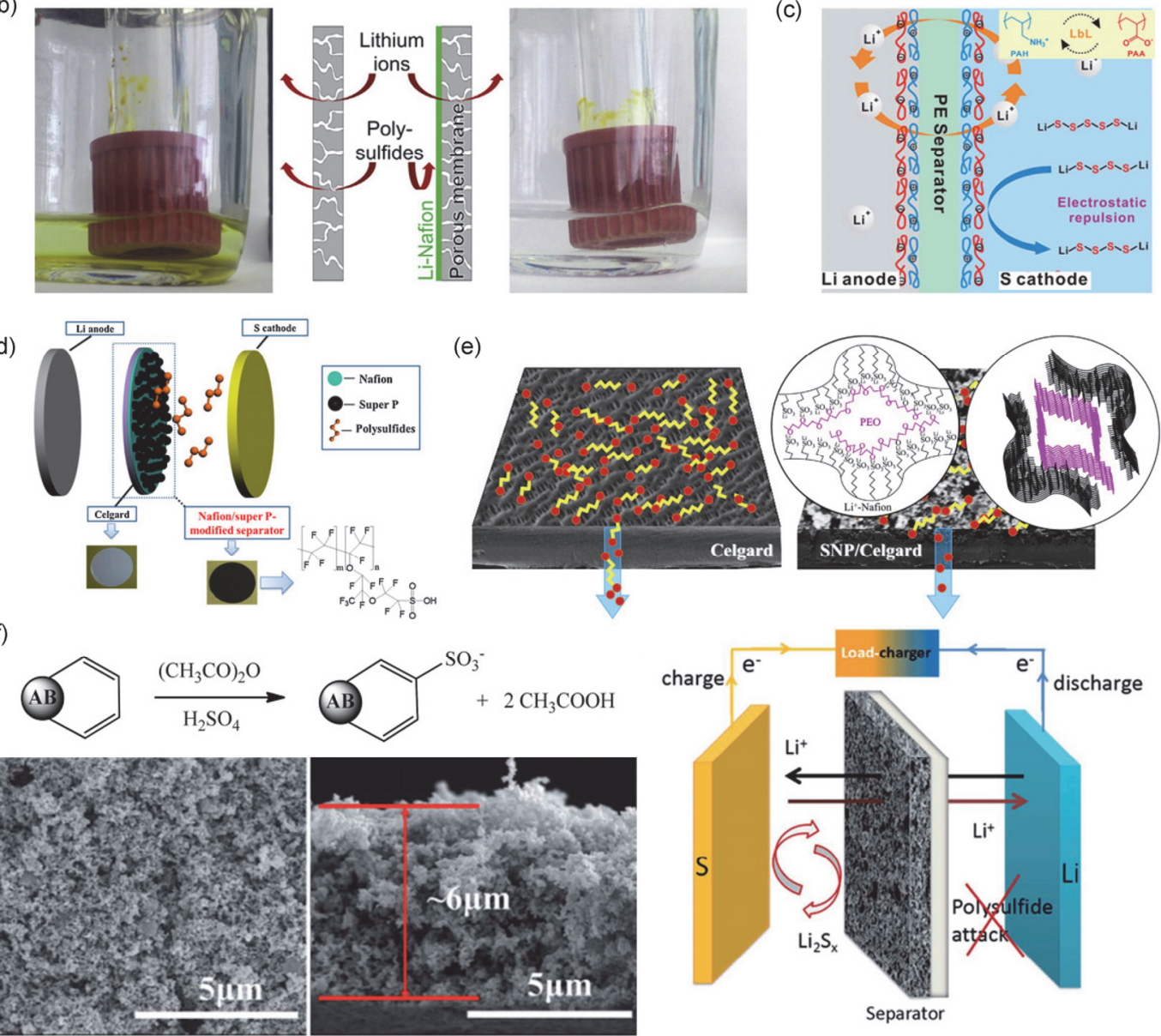

图 1 (a) 锂硫电池中采用常规多孔隔膜时存在穿梭效应, 以及采用 Nafion 负载的离子选择性隔膜抑制穿梭效应的示意图 ${ }^{[55]}$; (b) 采用锂化的 Nafion 修饰隔膜抑制多硫化物透过 ${ }^{[57]}$; (c) 利用高分子的层层自组装形成对锂离子具有选择性透过作用的隔膜 ${ }^{[65]}$; (d) 构建 Nafion/SuperP 导电炭 黑复合隔膜修饰层阻隔多硫化物的示意图 ${ }^{[62]}$; (e) 在隔膜表面构建 Nafion-SuperP-PEO 复合层抑制多硫化物扩散的示意图 ${ }^{[63]}$; (f) 采用磺化的乙炔 黑修饰隔膜, 并利用电荷排斥作用抑制多硫化物透过隔膜 ${ }^{[68]}$

Figure 1 (a) Scheme of Li-S battery with routine porous membrane that suffers from shuttle effect, compared with the Nafion-composite which prohibits shuttle of polysulfides ${ }^{[55]}$; (b) A lithiated Nafion-coating porous polymer separator that retards the shuttle of polysulfides in a working Li-S cell ${ }^{[57]}$; (c) A layer-by-layer assembled polymer separator that are permselective to lithium ions ${ }^{[65]}$; (d) Nafion/SuperP conductive carbon composite as a separator that impedes polysulfide ${ }^{[62]}$; (e) Surface coating of Nafion-SuperP-PEO composite to impede diffusion of polysulfides ${ }^{[63]}$; (f) A functional sulfonated acetylene black coated separator repulsing polysulfides through electrostatic interaction ${ }^{[68]}$

石墨烯材料具有典型的二维结构, 是一类表面化学 性质和官能团种类数量易于调变的材料平台. 石墨烯作 为一类重要的新兴材料, 其平面结构易于组装形成功能 隔膜. 氧化石墨烯隔膜可以作为一类快速的质子和水通
道实现选择性透过膜的功能 ${ }^{[71,72]}$. 本课题组采用氧化石 墨烯作为基元材料, 利用其二维结构特征构建薄膜材 料，利用氧化石墨烯片层间的孔隙实现锂离子的选择性 透过. 氧化石墨烯边缘的羧酸基团也具有一定通过静电 
排斥实现多硫化物阻隔的作用. 在 $0.1 \mathrm{C}$ 的充放电循环 过程中, 将库伦效率从 $60 \%$ 提升至 $95 \%$ 以上，同时将容 量衰减率降低至每个循环 $0.23 \%$ 以下 ${ }^{[73]}$. Lin 等 $^{[74]}$ 利用 还原氧化石墨烯薄膜修饰商用的 PP 隔膜, 类似地实现 了多硫化物阻隔的效果，同时由于还原氧化石墨烯具有 较高导电性, 还可以降低电池阻抗, 提升电池倍率性能. 北京理工大学陈人杰教授 ${ }^{[75]}$ 才利用硼酸修饰的方法 制备了硼掺杂的还原氧化石墨烯材料, 一方面利用含嗍 基团实现对多硫化物的高效吸附, 另一方面利用喼掺杂 带来的高电导率提升了硫利用率及大电流充放电性能. 近期, 斯坦福大学崔屹课题组 ${ }^{[76]}$ 利用二维的黑磷材料 修饰隔膜, 利用黑磷的二维结构堆砌成膜实现物理限 域, 同时利用多硫化物与黑磷表面较强的相互作用实现 化学限域. 另一方面, 黑磷膜层具有较高的导电性, 有 效实现了含硫组分的活化; 在与高含硫量正极配合使用 时大幅提高了锂硫电池正极的比容量及循环稳定性.

中科院沈阳金属所李峰课题组 ${ }^{[77]}$ 采用剥离石 墨烯 作为基元材料，分别通过隔膜涂覆，替换铝箔集流体， 构建具有石墨烯修饰隔膜以及石墨烯膜集流体的锂硫 电池构型. 其中, 石墨烯修饰的隔膜可有效减缓多硫化 物的跨膜输运, 从而极大地抑制了多硫化物在正负极之 间的穿梭效应. 运用三维 X 射线显微层析技术, 发现石 墨烯集流体可以有效地限域含硫组分. 该修饰隔膜中石 墨烯的层状结构可以抑制多硫化物的透过. 在 $0.3 \mathrm{~A} \cdot \mathrm{g}^{-1}$ 的电流密度下, 该锂硫电池构型具有 $1354 \mathrm{mAh} \cdot \mathrm{g}^{-1}$ 的 初始放电容量, 并且在 300 个循环内保持每个循环 $0.1 \%$ 的低容量损失率 ${ }^{[77]}$.

通过精确控制的膜层孔结构, 可以更有效地实现锂 离子的选择性透过功能. 日本工业技术院、南京大学周 豪慎研究组 ${ }^{[78]}$ 创造性的提出一种以金属-有机骨架化合 物(MOF)为基元材料的氧化石墨烯复合功能隔膜. 采用 $\mathrm{Cu}_{3}(\mathrm{BTC})_{2}$ 型 $\mathrm{MOF}(\mathrm{HKUST}-1)$ 作为 “离子篮” , 其典型 的孔道直径约为 $0.9 \mathrm{~nm}$, 远小于多硫化物的离子直径. 同时, 氧化石墨烯材料的层间距约为 $1.3 \mathrm{~nm}$, 小于多硫 化物的离子直径, 从而实现了锂离子的选择性透过. 采 用这种孔道精确设计的 MOF 隔膜, 可将锂硫电池的容 量衰减率在 1500 圈中降低至每圈 $0.019 \%$. 与纯氧化石 墨烯隔膜相比, MOF/氧化石墨烯复合隔膜降低了锂离 子输运阻力, 有效提升了锂硫电池的倍率性能. 通过改 变中心金属原子的种类, 该课题组 ${ }^{[79]}$ 近期发展了以 $\mathrm{Zn}(\mathrm{II})$ 为金属离子的 MOF 材料, 以其修饰隔膜可以获得 类似的提升锂硫电池稳定性, 降低多硫化物跨膜扩散的 效果.

近期, Helms 研究组 ${ }^{[80]}$ 根据模拟结果, 分析认为在 高分子膜材料孔道低于 $1.2 \sim 1.7 \mathrm{~nm}$ 时, 就有能力实现 多硫化物离子的选择性阻挡. 其通过高分子材料的设 计, 实现了具有本征微孔结构的高分子膜材料的构建, 孔道直径约为 $0.8 \mathrm{~nm}$. 实验结果证实, 此类孔道为 0.8 $\mathrm{nm}$ 的高分子膜对多硫化物的阻挡能力比普通 Celgard 隔膜提升 500 倍以上.
利用固态电解质的锂离子透过能力, 也可构建锂硫 电池中的多硫化物选择性阻挡层. $\mathrm{Li}$ 等 ${ }^{[81]}$ 报道了一种以 五氧化二钒为修饰材料的多功能隔膜, $\mathrm{V}_{2} \mathrm{O}_{5}$ 是一类高性 能固态锂离子导体. 锂离子可通过 $\mathrm{V}_{2} \mathrm{O}_{5}$ 层间进行传输, 而多硫化物难以通过 $\mathrm{V}_{2} \mathrm{O}_{5}$ 功能层, 因此可实现锂离子 的选择性透过. Manthiram 课题组 ${ }^{[82]}$ 利用 LiSICON 型固 体电解质在锂硫电池中实现了锂离子的选择性透过, 并 通过在固体电解质层和负极间构建 “柔性” 中间层部分 解决金属负极与固体电解质间的接触问题.

\subsection{3 通过吸附效应抑制多硫化物扩散}

除了通过电荷以及空间限域作用外，利用多功能隔 膜对多硫化物的吸附作用也可以实现锂离子的选择性 透过，抑制多硫化物的扩散. 主要分为两类，第一类通 过构建具有丰富微孔的膜层结构实现物理吸附, 利用多 硫化物与锂离子的扩散系数方面的差异实现锂离子的 选择性透过功能; 第二类中往往通过多硫化物与功能层 之间较强的化学吸附实现多硫化物的针定.

中南大学张治安课题组 ${ }^{[83]}$ 提出一类采用三氧化二 铝修饰的隔膜体系. 利用颗粒三氧化二铝在隔膜表面形 成了一个多孔层, 其孔道可以实现锂离子的高速透过, 而多硫化物通过曲折孔道的能力较弱, 扩散受到多孔层 的抑制. Manthiram 课题组 ${ }^{[84]}$ 采用活化的碳纳米纤维作 为功能层, 其中活化碳纳米纤维具有本征的微孔结构, 且其组装形成的功能层同样具有丰富的微孔结构. 这两 级的微孔结构均对多硫化物具有物理吸附作用, 强化了 对多硫化物的吸附阻隔作用. 北京大学夏定国研究团 队 ${ }^{[85]}$ 利用 PVDF 混合炭黑颗粒对隔膜进行修饰, 提升了 循环稳定性. 该修饰层主要利用了炭黑颗粒表面大量微 孔对多硫化物的物理吸附较好地实现了多硫化物的限 域作用. 北京理工大学孙克宁研究团队 ${ }^{[86]}$ 采用碳纳米 纤维/PVDF 复合隔膜吸附多硫化物, 同样有效减少了多 硫化物的穿梭现象. 北京化工大学黄雅钦课题组 ${ }^{[87]}$ 采 用乙炔黑和明胶粘结剂混合修饰隔膜，其中乙炔黑构成 的孔道对多硫化物所具有的物理吸附效应配合明胶对 多硫化物的部分化学吸附作用, 可以形成多硫化物阻挡 层, 提升锂硫电池循环稳定性. 近期, 该课题组 ${ }^{[88]}$ 进一 步采用蟹壳作为生物质原料, 制备了一类氢氧化钻-碳 复合骨架材料, 利用多孔结构实现对多硫化物的吸附并 降低穿梭效应.

通过引入部分氧化物, 可实现对多硫化物的化学吸 附. Lapornik 等 ${ }^{[89]}$ 采用锰修饰的硅分子篎实现了类似的 物理及化学吸附作用的集成，利用分子篮的多孔结构以 及 $\mathrm{Mn}_{2} \mathrm{O}_{3}$ 的氧化物对多硫化物的化学吸附性质, 成功实 现了对玻璃纤维隔膜的修饰, 提升了锂硫电池的循环稳 定性. Nair 等 ${ }^{[90]}$ 采用纤维素作为前驱物, 通过热聚合获 得具有吸附多硫化物功能的聚合物电解质作为隔膜, 可 以提供高离子导率, 赋予锂硫电池活性材料具有高利用 效率. Qian 等 ${ }^{[91]}$ 在隔膜表面修饰科琴黑与 $\mathrm{MnO}$ 的混合 物. 科琴黑本身对多硫化物具有一定的物理吸附作用, 
(a)

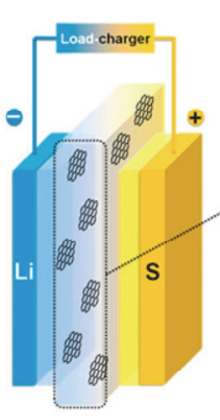

(b)

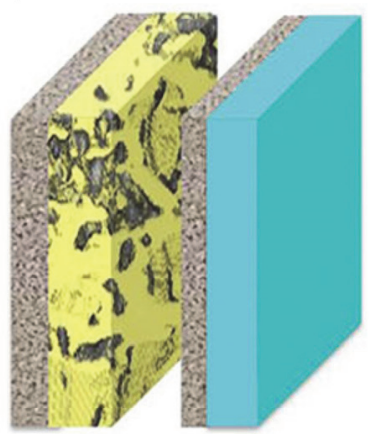

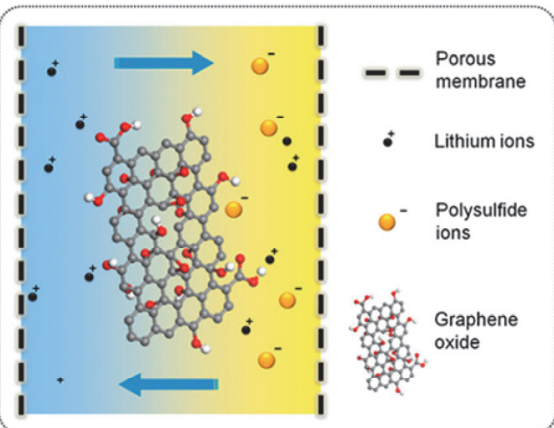

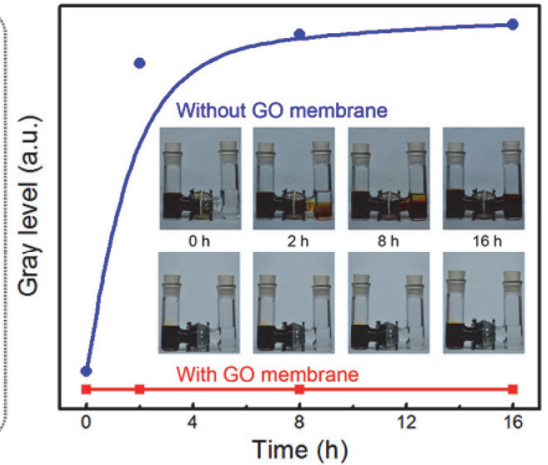

(c)
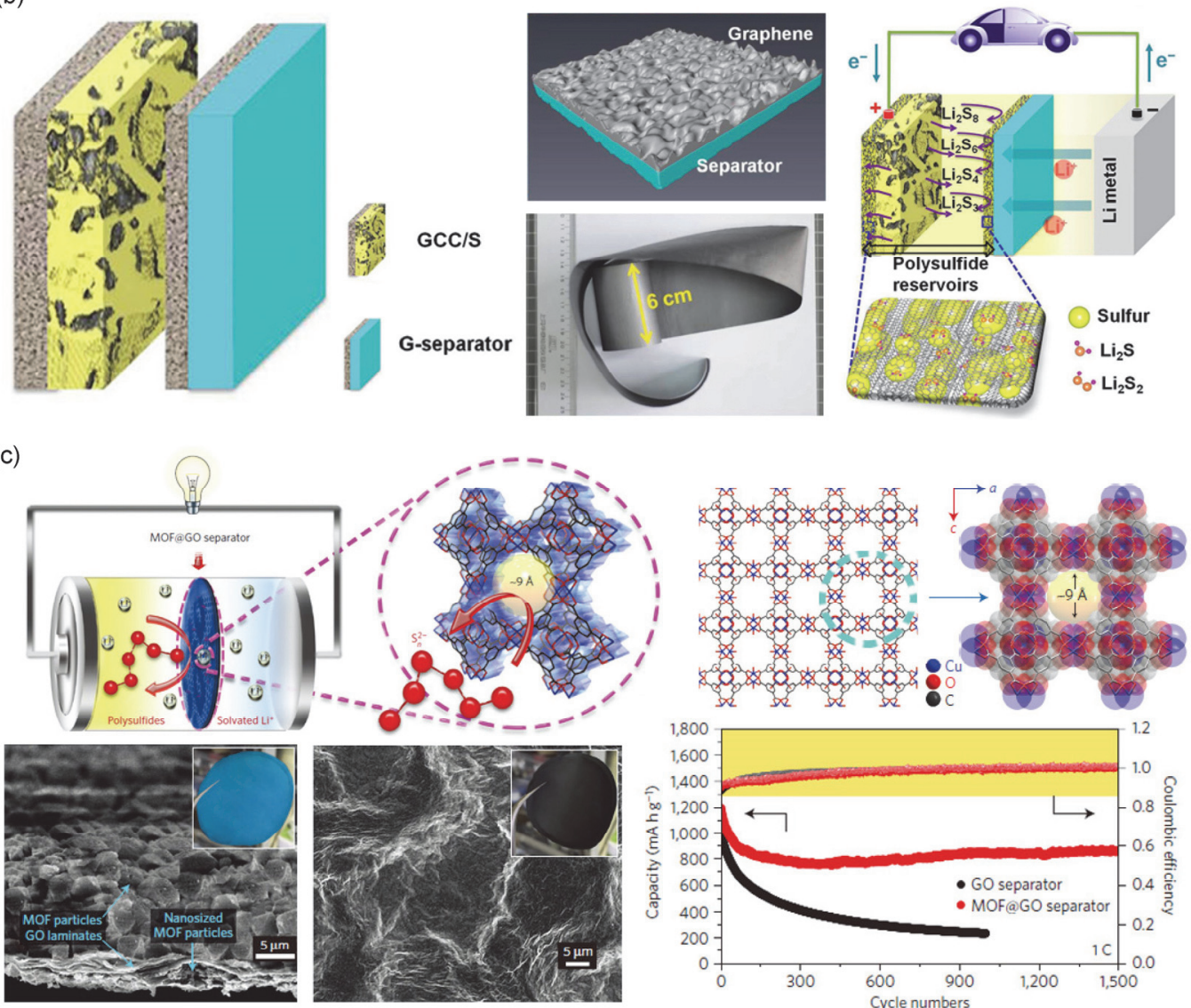

(d)
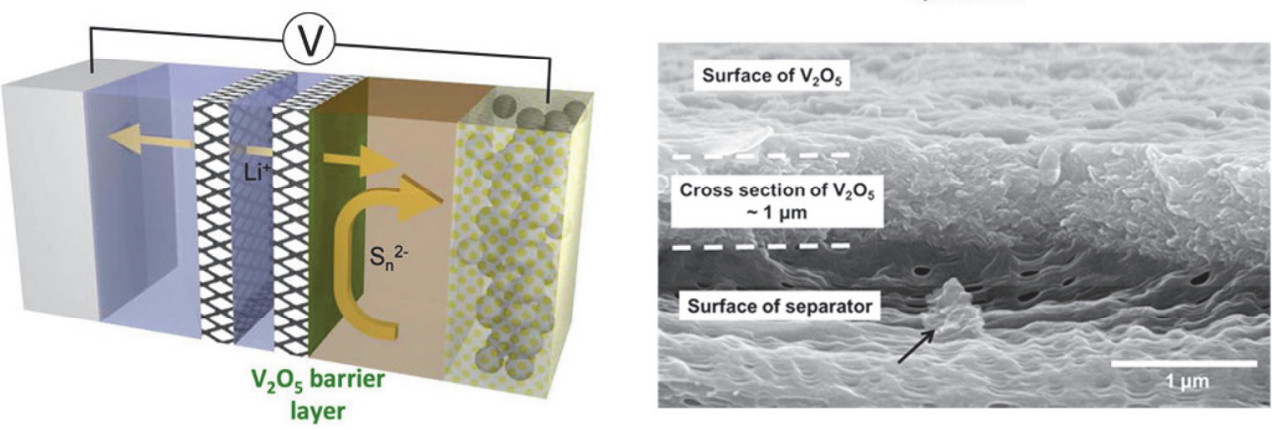

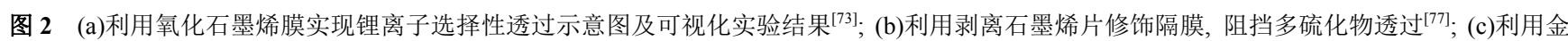
属有机骨架材料修饰隔膜, 利用 $0.9 \mathrm{~nm}$ 的孔道阻碍多硫化物透过, 实现 1500 个充放电循环内的超高稳定性 ${ }^{[78]}$; (d) 利用 $\mathrm{V}_{2} \mathrm{O}_{5}$ 作为锂离子导体实现 对多硫化物的选择性阻挡 ${ }^{[82]}$

Figure 2 (a) Scheme of a graphene oxide based membrane as a permselective separator and the related visible test of polysulfide shuttle in a Li-S cell ${ }^{[73]}$; (b) An exfoliated graphene modified separator impeding shuttle of polysulfides ${ }^{[77]}$; (c) Scheme of MOF modified membrane with $0.9 \mathrm{~nm}$ pores prohibiting shuttle effect and a cell with 1500 cycles ${ }^{[78]}$; (d) Scheme of $\mathrm{V}_{2} \mathrm{O}_{5}$ as lithium ion conductor to repulse the shuttle of polysulfides and the cross-section image. $^{[82]}$ 
而 $\mathrm{MnO}$ 的添加有效提升了材料对多硫化物的化学吸附 能力, 二者共同作用大幅增加了该功能层的多硫化物吸 附量. 作为具有一定导电性的功能涂层, 该隔膜对降低 正极界面传递阻力也有积极作用. 卧龙岗大学郭再萍 等 ${ }^{[92]}$ 采用碳作为隔膜表面层吸附多硫化物, 创造性的 提出碳一硫-碳基隔膜三明治构型, 实现高载硫下硫的高 效利用. 国家纳米中心智林杰课题组 ${ }^{[93]}$ 将氧化石墨烯 和氧化碳纳米管的混合基元材料通过喷涂成膜的方法 构建多功能膜层, 膜层负载量仅为 $0.3 \mathrm{mg} \cdot \mathrm{cm}^{-2}$. 该膜层 中的纳米碳材料中的大量含氧官能团对多硫化物具有 针定作用, 极大的抑制了锂硫电池中的穿梭效应及其带 来的容量衰减. 另一方面, 混合膜中氧化碳纳米管的存 在使氧化石墨烯膜中存在充足的通道保证锂离子的快 速迁移. 因此, 利用该多功能隔膜的锂硫电池可在 100 个循环后保持 $750 \mathrm{mAh} \cdot \mathrm{g}^{-1}$ 以上的比容量, 远高于采用 普通隔膜的电池. 防化科学研究院的王维坤研究员与北 京化工大学赵秀英教授课题组 ${ }^{[94]}$ 合作, 报道了一类利 用氧化碳纳米管与 LA132 粘结剂混合涂覆制备的多功 能隔膜, 通过官能团化碳纳米管的物理及化学吸附作 用, 有效提升了锂硫电池的性能.

利用含氮官能团与多硫化物具有较强结合能的特 点, 通过在隔膜功能层中引入氮元素也可以起到较好的 多硫化物吸附作用 ${ }^{[95]}$. Chang 等 ${ }^{[96]}$ 利用聚苯胺纳米纤维 以及碳纳米管共同构建了超轻的多功能层, 这一杂化的 功能层对锂硫电池具有多方面的提升: 多壁碳纳米管构 成的孔道和缺陷对多硫化物具有物理吸附作用; 聚苯胺 纳米纤维中的亚胺基团对多硫化物具有显著的化学吸 附作用; 该功能层作为导电层还可以显著降低正极表面 的反应阻抗. 采用相似的聚丙烯腈纳米纤维/氧化石墨 烯复合隔膜结构, 也可以利用含氮基团以及含氧基团对 多硫化物的化学吸附作用, 抑制多硫化物的扩散 ${ }^{[97]}$. 北 京理工大学孙克宁研究团队 ${ }^{[97]}$ 采用碳纳米纤维/PVDF 复合隔膜吸附多硫化物, 类似地减少多硫化物的穿梭现 象. Zhou 等以聚吡咯纳米线为前体, 通过活化及炭化过 程获得了氮含量高达 $7.12 \mathrm{wt} \%$ 的多孔碳纳米纤维. 氮杂 原子的理性引入, 不仅可以提升材料的导电性, 还可以 实现对多硫化物的物理和化学吸附 ${ }^{[98 \sim 101]}$. 因此, 利用 该含氮多孔碳纳米线修饰隔膜, 可降低正极界面电阻, 改善电极界面, 实现硫活性材料的高效稳定利用 ${ }^{[102]}$. Balach 等 ${ }^{[103]}$ 也报道了以氮掺杂的介孔碳作为多硫化物 吸附介质构建多功能隔膜的工作.

苏州纳米所靳健课题组 ${ }^{[104]}$ 设计了采用少层碳化钛 $\left(\mathrm{Ti}_{3} \mathrm{C}_{2}\right)$ 纳米片修饰的玻璃纤维隔膜来抑制多硫化物的 跨膜扩散. 第一性原理计算结果显示, 通过 $\mathrm{Ti}$ 原子与 $\mathrm{S}$ 原子的相互作用, 碳化钛纳米片与多硫化物具有很高的 结合能力. 因此, 少层碳化钛纳米片不仅提供额外的导 电性, 还可以有效吸附多硫化物 ${ }^{[104]}$. 导电的碳化钛能 够有效的吸附多硫化物, 并提供电子通路, 实现吸附多 硫化物的氧化还原反应 ${ }^{[105]}$. 温州大学杨植等 ${ }^{[106]}$ 采用石
墨烯-二氧化钛复合膜吸附多硫化物，促使溶解的多硫 化物限域在正极中, 减少可溶多硫化物扩散到负极的通 量，从而实现活性硫材料的稳定利用. 近期，悉尼科技 大学汪国秀教授 ${ }^{[107]}$ 带领的研究团队提出采用 $\mathrm{Ti}_{3} \mathrm{C}_{2} \mathrm{~T}_{x}$ 类 MXene 材料修饰隔膜，同样利用 $\mathrm{Ti}$ 金属与硫之间的相 互作用实现了多硫化物的高效吸附提升了电池的稳定 性.

\section{2 改善正极隔膜界面的多功能隔膜}

除了赋予多功能隔膜阻挡多硫化物的能力，使其大 幅降低理硫电池中的 “穿梭效应” 外，其也可以在正极 一侧通过改善正极隔膜界面来提升电池的性能. 在锂硫 电池循环过程中，正极表面的阻抗由于表面结构的改变 会逐渐上升, 随着多硫化物逐渐溶出含硫活性组分也会 逐渐损失. 通过改善正极与隔膜的界面, 可以从降低正 极隔膜界面电阻以及回收活性硫材料两方面提升锂硫 电池性能.

\subsection{1降低正极界面电阻的多功能隔膜}

采用导电的碳层修饰隔膜，以降低正极界面电阻， 促进电化学反应的进行是一类重要的方法. Manthiram 课题组 ${ }^{[95,108 ~ 111]}$ 报道了一系列应用碳修饰隔膜的研究工 作. 例如, Manthiram 课题组采用 SuperP 导电碳微球, 在 隔膜表面实现了导电碳颗粒功能层的涂覆. 一方面, SuperP 导电层可以有效地起到正极表面 “上层集流体” 的作用，有效降低电池运行过程中的阻抗；另一方面， 该碳层也对多硫化物的扩散具有一定抑制作用. 采用这 种隔膜时, 锂硫电池可获得 $1400 \mathrm{mAh} \cdot \mathrm{g}^{-1}$ 的较高初始 比容量, 在 200 个充放电循环内保持每个循环 $0.2 \%$ 左右 的较低容量衰减速率 ${ }^{[111]}$. 中南大学张治安课题组 ${ }^{[112]}$ 采 用导电炭黑涂覆的隔膜，在不添加硝酸理的情况下实现 了 $90 \%$ 以上的库伦效率. 通过电化学阻抗谱表征该多功 能隔膜对正极界面的电荷传递阻力, 结果显示等效电荷 传递阻抗 $R_{\mathrm{ct}}$ 值由 $16 \Omega$ 降低至 $8 \Omega$, 使电池的大电流充 放电性能得到显著提升, 电池在 $2 \mathrm{C}$ 放电情况下可保留 $0.5 \mathrm{C}$ 下 $70 \%$ 以上的放电容量. 上海硅酸盐研究所的温 兆银课题组 ${ }^{[113]}$ 采用碳纳米管和导电炭黑复合作为电子 导电介质, 固体电解质 LAGP 颗粒作为锂离子导体共混 合，获得了同时具有电子和离子导通能力的多功能修饰 层. 配合该隔膜组装的锂硫电池在不同充放电深度下的 阻抗测试均小于传统的商用隔膜以及单一导电碳层修 饰的隔膜. 固体电解质颗粒的加入有效提升了离子电导 率, 使该电池获得了较优的比容量. 近期, $\mathrm{Zhu}$ 等 ${ }^{[114]}$ 在 具有高孔隙率的玻璃纤维隔膜负载导电碳层, 获得具有 极高正极活性材料利用率，且体现极佳倍率性能的锂硫 电池多功能隔膜. 该导电碳层降低了正极界面阻抗, 提 升正极硫材料的利用率，同时对多硫化物的跨膜扩散也 起到一定的阻挡作用. Zhao 等 ${ }^{[115]}$ 也报道了利用导电碳 层修饰隔膜, 促进正极表面的电子和离子传递, 获得了 优异的倍率性能. 其他高性能的碳材料, 
(a)
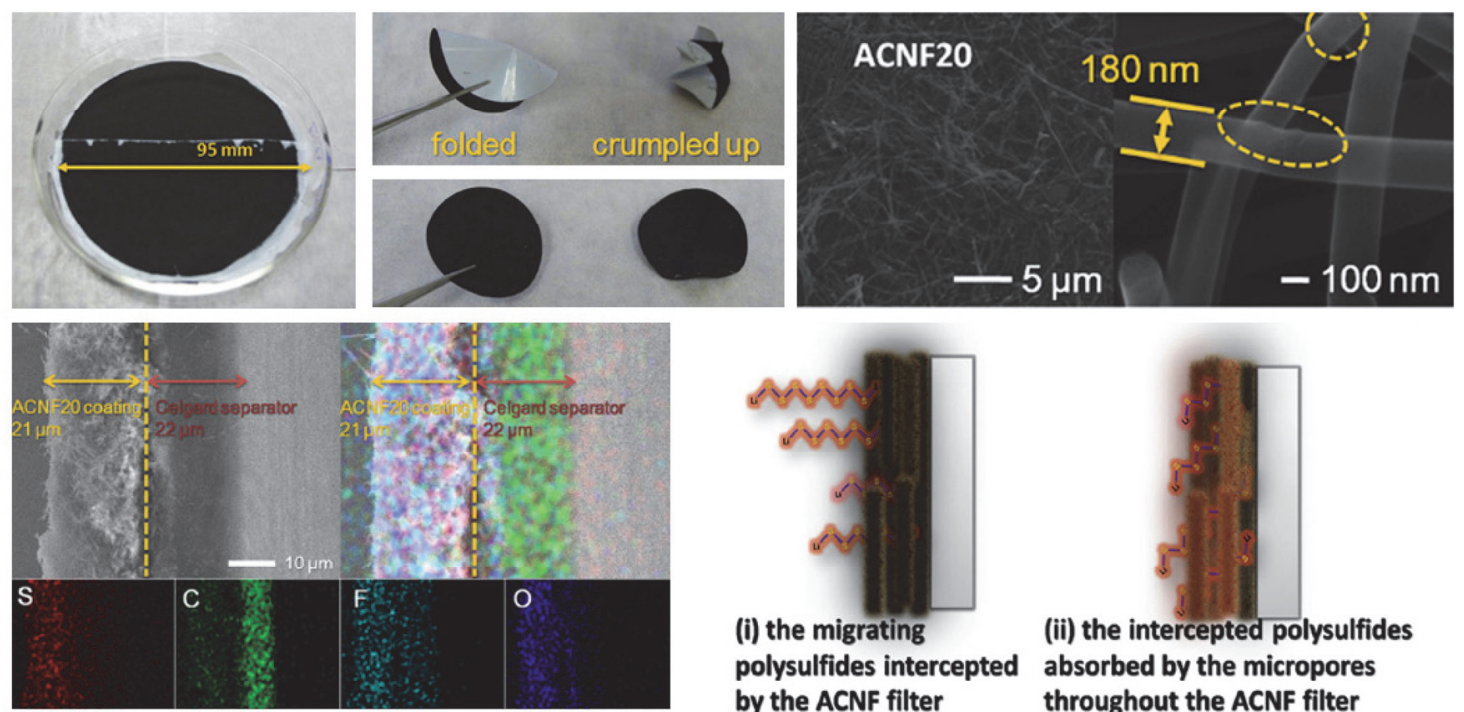

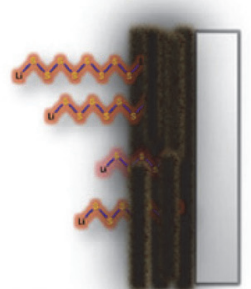

(i) the migrating

$\begin{array}{ll}\text { (i) the migrating } & \text { (ii) the intercepted polysulfides } \\ \text { polysulfides intercepted absorbed by the micropores }\end{array}$ by the ACNF filter throughout the ACNF filter

(b)

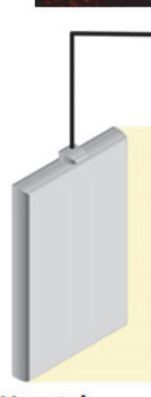

Li metal
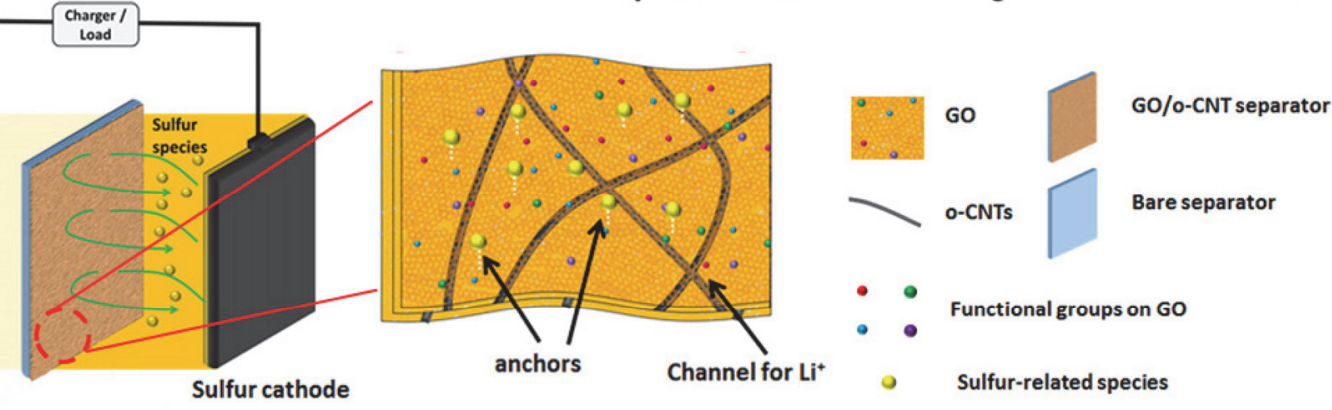

- Functional groups on GO

Sulfur-related species

(c)
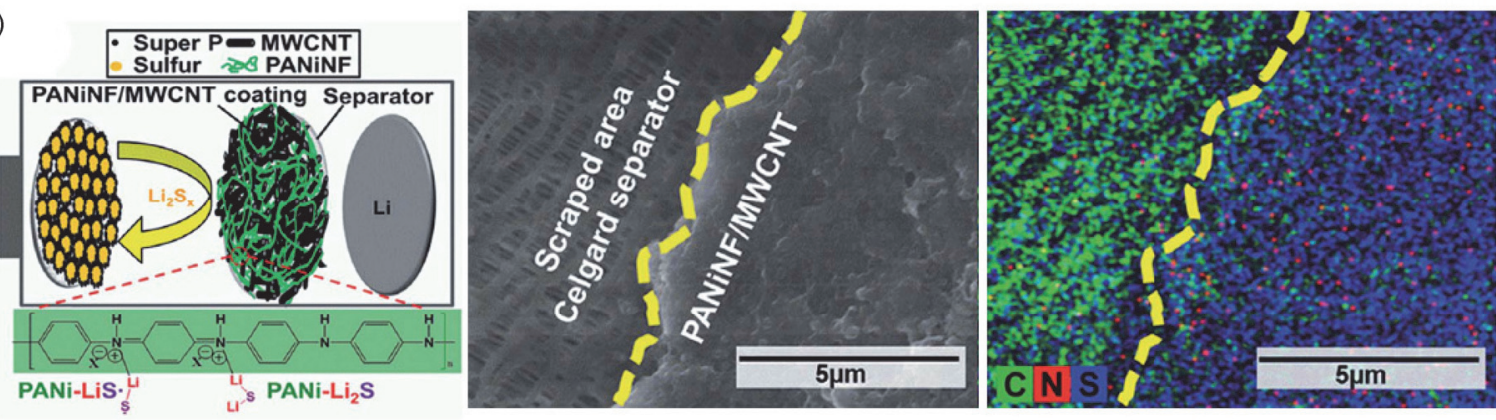

(d)
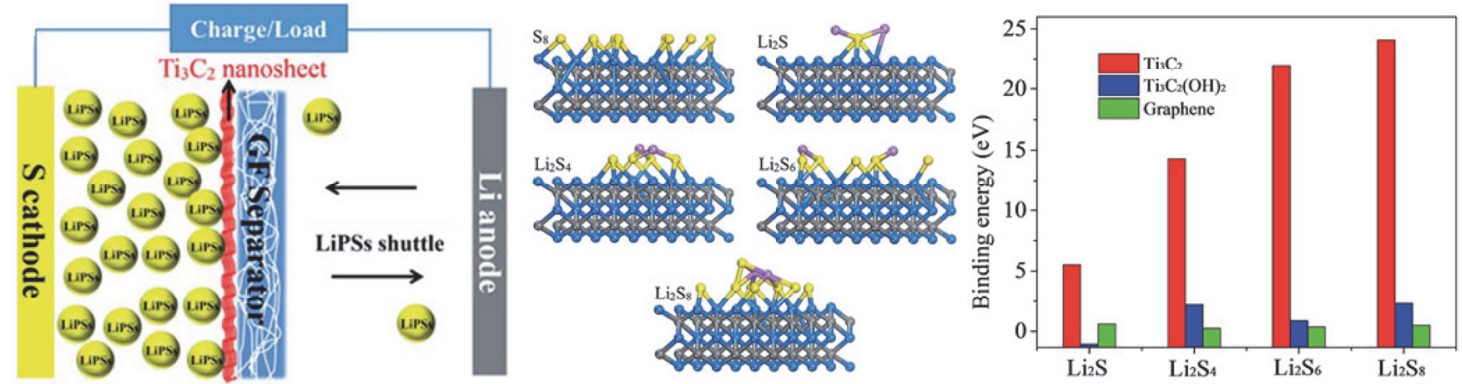

图 3 (a) 利用活化碳纳米纤维构建具有多级微孔的隔膜, 并通过纳米纤维自身微孔及组装形成的孔结构对多硫化物形成物理吸附 ${ }^{[84]}$; (b) 利用氧 化石墨烯和氧化的碳纳米管构建修饰层, 利用含氧官能团对多硫化物实现吸附, 抑制其扩散 ${ }^{[93]}$; (c) 以聚苯胺纳米纤维和碳纳米管共同形成功能 层, 同时实现对多硫化物的物理和化学吸附 ${ }^{[96]}$; (d) 利用碳化钛中 $\mathrm{Ti}$ 原子与 $\mathrm{S}$ 离子较强的结合能实现对多硫化物的吸附 ${ }^{[104]}$

Figure 3 (a) Scheme of activated carbon nanofiber coated porous membrane, in which the micro/mesopore are constructed by assembled nanofiber, achieving strong physical absorption to polysulfides ${ }^{[84]}$; (b) Scheme of the GO/o-CNT coated separator achieving absorption to polysulfide and repulsion of

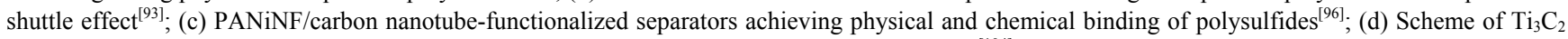
modified separator that absorbs polysulfides based on the strong binding between $\mathrm{Ti}$ and $\mathrm{S}$ atoms ${ }^{[104]}$ 
(a)
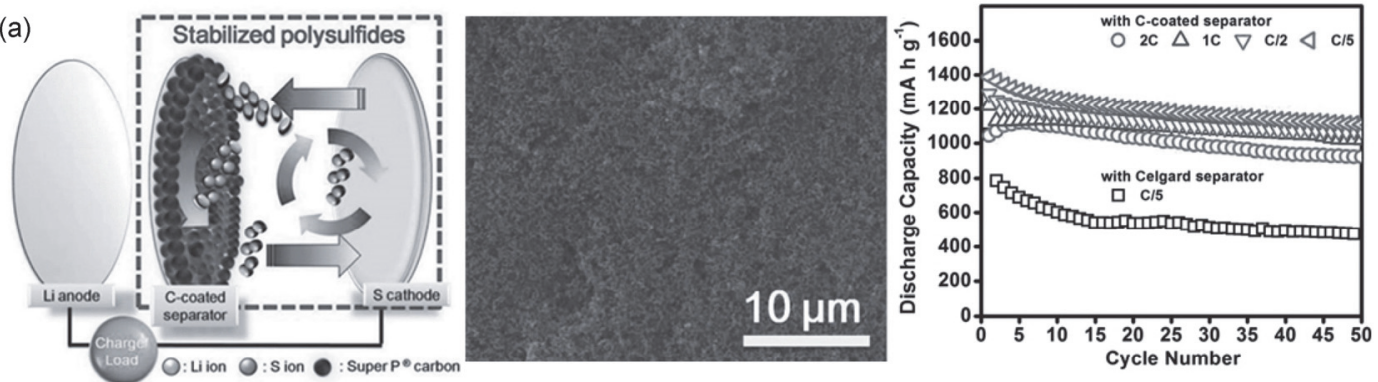

(b)
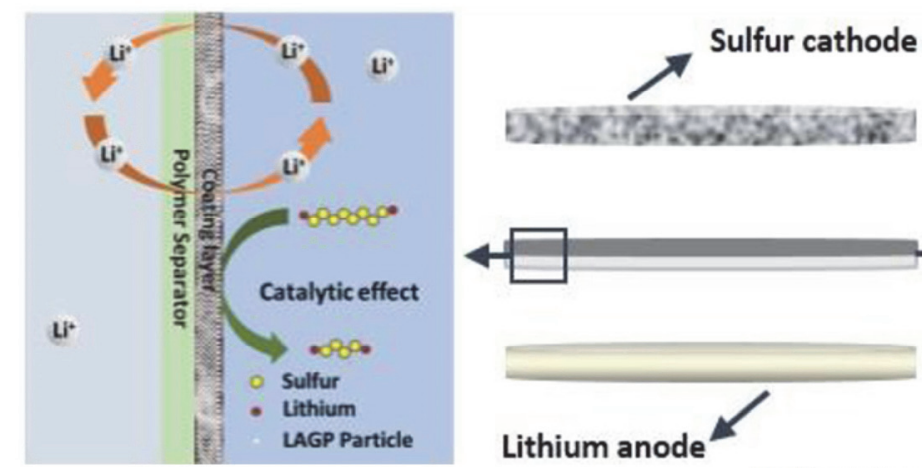

(c)

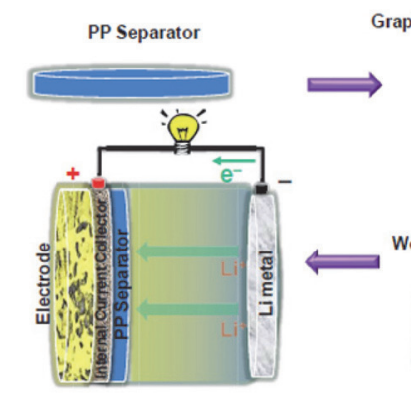
Graphene Coated on PP Separator as
Internal Current Collector

(d)
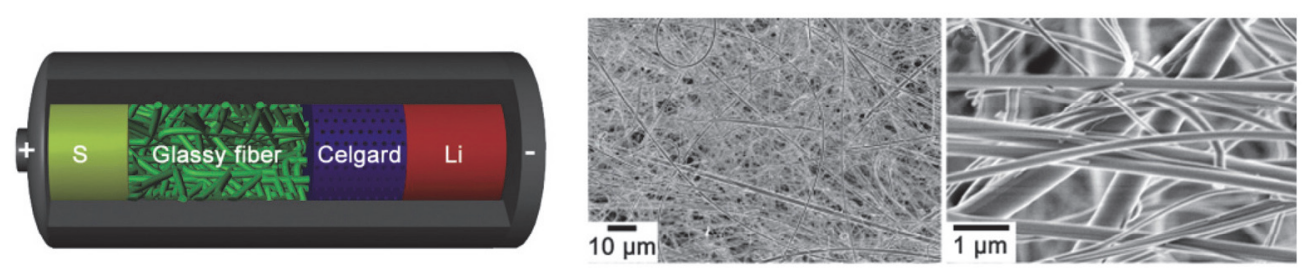

(e)
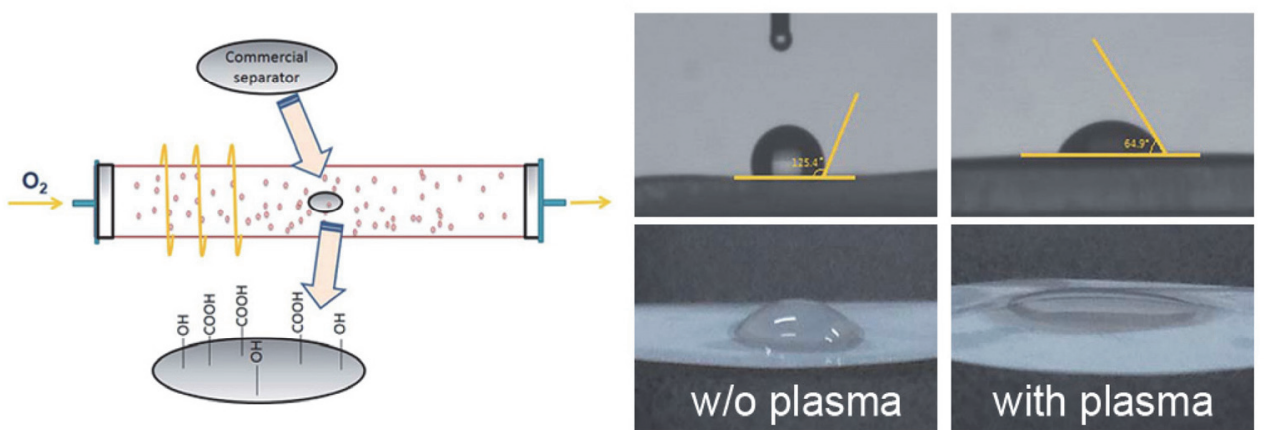

图 4 （a）在隔膜表面采用 SuperP 导电炭黑修饰改善正极界面反应示意图 ${ }^{[111]}$; (b) 在隔膜表面采用导电炭黑及固体电解质颗粒修饰，同时构建电 子及离子导电通路改善界面反应示意图 ${ }^{[13]}$; (c) 在石墨烯修饰隔膜表面直接涂覆正极材料, 获得柔性的聚丙烯-石墨烯-硫复合正极隔膜材料, 并

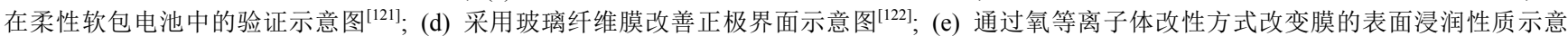
图 $^{[124]}$

Figure 4 (a) Scheme of SuperP conductive carbon modified cathode surface for high performance Li-S battery ${ }^{[111]}$; (b) A composite separator coated by conductive carbon and solid electrolyte composite that enhances electron and ion conduction ${ }^{[113]}$; (c) Scheme of flexible polypropylene-graphene-sulfur composite cathode, by direct coating of cathode materials onto graphene-modified separator for flexible pouch cells ${ }^{[121]}$; (d) Scheme of glass fiber modified separator/cathode interface ${ }^{[122]}$; (e) Plasma-engraved nanosheets to improve wettability for high performance Li-S battery ${ }^{[124]}$ 
包括多壁碳纳米管 ${ }^{[109]}$, 介孔碳 ${ }^{[116]}$, 这些导电隔膜涂层 均有效改善了正极界面反应, 提升了电池的循环稳定 性. 如果隔膜表面涂覆的碳材料能够引入杂原子 ${ }^{[117]}$ 或 者极性聚合物 $\mathrm{PEG}^{[118,119]}$ 或壳聚糖 ${ }^{[120]}$, 就可促进多硫化 物的吸附, 从而提升复合隔膜对于多硫化物的吸附.

中科院沈阳金属所李峰研究团 ${ }^{[121]}$ 队将石墨烯修饰 隔膜和正极活性材料层直接结合起来, 通过直接将正极 浆料涂覆在石墨烯修饰隔膜的石墨烯一侧, 获得了柔性 的聚丙烯-石墨烯一硫复合正极隔膜材料. 这一构型省去 铝䈃集流体结构, 改善电极的强度和柔性, 降低电化学 反应阻抗, 提升电解液润湿性能. 从性能上看, 在 0.3 $\mathrm{A} \cdot \mathrm{g}^{-1}$ 的测试电流下, 正极在 $70 \%$ 以上的高硫含量情况 下仍可获得 $1200 \mathrm{mAh} \cdot \mathrm{g}^{-1}$ 以上的比容量. 同时, 在 500 个循环中单圈的容量衰减率仅为 $0.064 \%$ 左右, 具有极 佳的循环稳定性. 由于该正极隔膜复合材料具有柔性特 征, 因此可组装成柔性电池并在弯折情况下实现充放电 过程 ${ }^{[121]}$.

利用廉价的玻璃纤维材料, 复旦大学王永刚、夏永 姚研究团队 ${ }^{[122]}$ 报道了锂硫电池中的高效玻璃纤维隔膜 材料. 该材料具有丰富的孔道结构有利于电解液的浸 润; 极高的电解液持液量, 有利于锂离子的传输; 极高 的热稳定性, 可降低电池安全风险. 在锂硫电池正极一 侧应用时, 能有效改善电池的循环性能. $\mathrm{Zhu}$ 等 ${ }^{[123]}$ 详细 分析了玻璃纤维隔膜作为锂硫电池隔膜时起到的作用, 认为多孔的剥离纤维隔膜的多孔结构提升了电解液持 液量, 与商用聚丙烯隔膜相比在大电流充放电性能等方 面具有显著优势. 这可以减缓多硫化物向负极的扩散, 对负极保护及循环稳定性具有重要贡献.

中南大学王双印课题组 ${ }^{[124]}$ 通过对商用 Celgard 隔 膜的氧气等离子处理, 在表面接枝了大量羧基、羟基等 含氧基团. 这些官能团的存在有效改善了隔膜电解液润 湿性能以及导离子能力, 有效降低了电池界面阻抗, 改 善了电池的循环性能. 利用聚多巴胺修饰隔膜的也具有 提高隔膜可润湿性能的作用. $\mathrm{Li}$ 等 ${ }^{[125]}$ 以及 Zhang 等 ${ }^{[126]}$ 报道, 利用多巴胺修饰的方法, 可以将商用隔膜的表面 改为亲水性质, 并提高其电解液的持液量. 在锂硫电池 中应用时, 多巴胺修饰的隔膜可有效降低理硫电池中的 界面电荷传递阻力. 上海硅酸盐研究所的温兆银课题 组 ${ }^{[127]}$ 采用聚吡咯纳米管及纳米线修饰隔膜, 利用其导 电高分子特性及更好的电解液润湿性能, 有效降低了界 面阻抗，并提高电池的循环稳定性.

\subsection{2 实现活性硫材料回收的多功能隔膜}

正极硫材料在充放电过程中逐渐被还原为多硫化 物, 将不可避免地溶出并扩散至隔膜. 进一步还原的多 硫化物易在正极表面隔膜孔道中沉积, 从而形成惰性 层, 阻碍电子、离子传输, 使电化学过程难以高效进行. 这是锂硫电池容量低且衰减快的主要原因之一. 如能有 效设计一类可以回收电极表面及隔膜中 “死硫” 的导电
隔膜功能层, 将大幅提高锂硫电池的循环稳定性.

美国斯坦福大学的崔屹课题组 ${ }^{[128]}$ 提出了一种通过 导电碳层负载, 抑制活性硫材料流失, 实现惰性含硫组 分回收的策略. 通过对锂硫电池充放电循环后隔膜的详 细测试显示: 使用常规隔膜时, 即使放电到 $1.7 \mathrm{~V}$ 时隔 膜中仍滞留大量含硫组分; 而采用具有导电碳层的隔膜 时, 循环测试后的隔膜呈现较浅的颜色, 说明留存在隔 膜中的含硫组分的量大幅降低. 对隔膜中含硫组分的活 化和再利用有效促进了锂硫电池循环稳定性的提升. Chung 等 ${ }^{[110]}$ 提出了微孔碳/聚乙二醇复合涂层，这一涂 层中具有丰富的孔结构, 具有较高持液量. 其中的微孔 碳材料对多硫化物具有物理吸附作用，而聚乙二醇材料 起到部分化学吸附功能. 同时, 由于复合涂层同时具有 较高的导电性, 其可以有效对吸附的含硫组分进行回收 利用. 该多功能隔膜获得了 $1307 \mathrm{mAh} \bullet \mathrm{g}^{-1}$ 的比容量, 并 且在 500 个电化学循环中保持 $0.11 \%$ 以下的单圈衰减率.

通过对隔膜表面纳米碳材料结构设计，本课题组提 出了一类用以改善锂硫电池的性能的不对称隔膜. 该隔 膜具有双层结构，一层是商用 Celgard 隔膜，用以实现 电子绝缘并提供机械强度; 另一层是石墨烯骨架碳层, 用以回收、储存正极与隔膜界面的含硫活性组分. 该石 墨烯骨架碳材料由少层石墨烯组成, 具有高达 2100 $\mathrm{m}^{2} \cdot \mathrm{g}^{-1}$ 的比表面积以及 $3.01 \mathrm{~cm}^{3} \cdot \mathrm{g}^{-1}$ 的介孔孔容, 具有 很高的的导电性和容纳固体产物的能力. 此类不对称隔 膜上的碳负载量仅为 $0.3 \mathrm{mg} \cdot \mathrm{cm}^{-2}$, 可与硫含量和面负 载量分别高达 $80 \%$ 和 $5.3 \mathrm{mg} \cdot \mathrm{cm}^{-2}$ 的硫正极配合使用, 将容量从 $2.6 \mathrm{mAh} \cdot \mathrm{cm}^{-2}$ 提升至 $5.6 \mathrm{mAh} \cdot \mathrm{cm}^{-2}$, 且 120 圈循环后容量基本保持不变 ${ }^{[129]}$. 在利用多孔石墨烯结 构提升对含硫组分的物理吸附和转化的基础上, 本研究 才队进一步提出向隔膜功能层引入化学吸附和催化转 化特性, 从而进一步改善隔膜再生含硫组分的功能. 具 体的，采用氮掺杂的介孔石墨烯结构为骨架，通过原位 生长的方式在其中组装 $\mathrm{NiFe}$ 层状双金属氢氧化物(小于 $5 \mathrm{~nm}$. 利用纳米 $\mathrm{NiFe}$ 层状双金属氢氧化物的 “亲硫” 特 性与氮掺杂介孔石墨烯的 “亲锂” 特性实现对多硫化锂 的双功能吸附, 实现对多硫化物的捕捉及电化学催化转 化 ${ }^{[130]}$. 验证性实验也证实, 该复合材料可以有效催化 可溶多硫化物向固相 $\mathrm{Li}_{2} \mathrm{~S}$ 的电化学转化. 因此, 采用了 该复合隔膜制备的锂硫电池具有高容量, 高倍率性能和 高循环稳定性的特点.

\section{3 改善负极隔膜界面的多功能隔膜}

锂硫电池中采用的锂金属具有极高的比容量(3860 $\left.\mathrm{mAh} \cdot \mathrm{g}^{-1}\right)$ 和最负的电势 $(-3.040 \mathrm{~V}$ vs. 标准氢电极), 是 锂硫电池具有极高理论能量密度的重要原因. 然而, 金 属锂负极的应用长期受制于其锂枝晶生长造成的安全 性问题，难以被市场接受. 针对锂金属二次电池发展, 具有高利用率，高循环效率，无枝晶生长的金属锂负极 
(a)

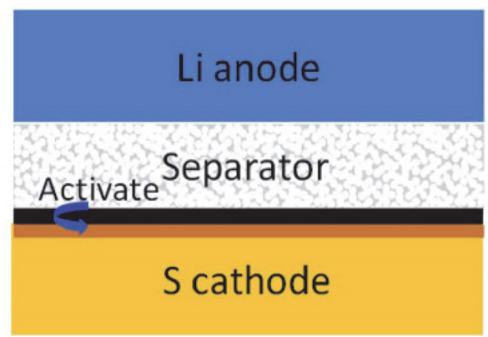

(b)

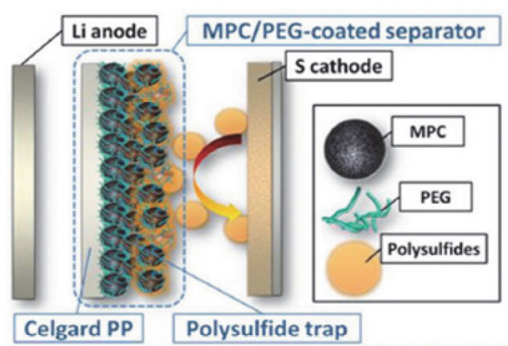

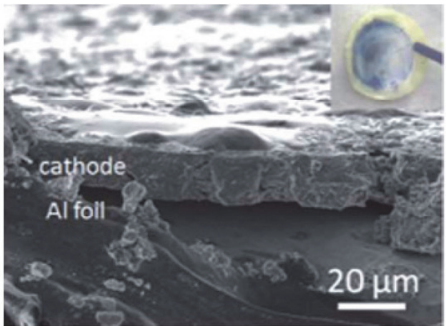
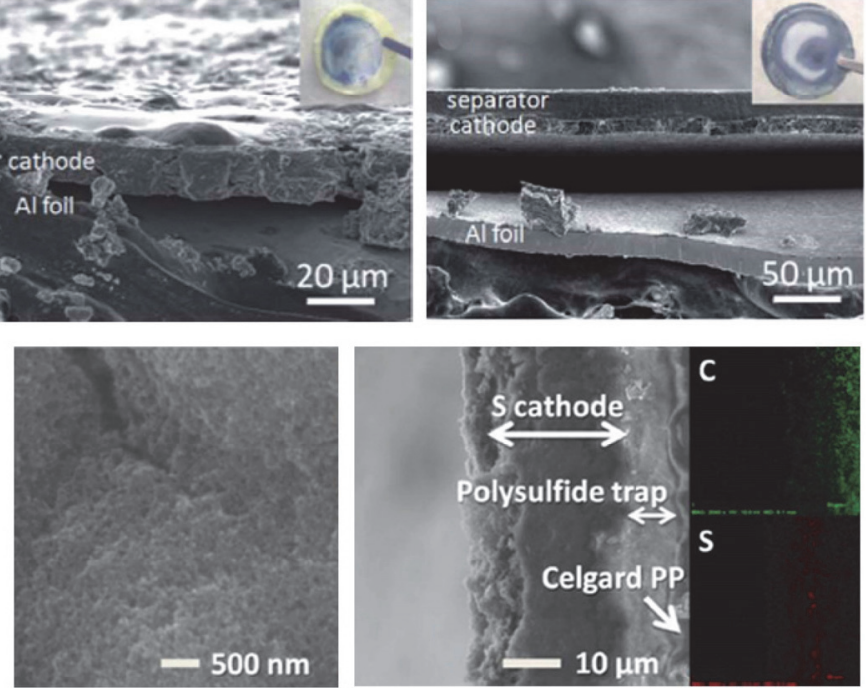

Janus separator for Li-S battery

(c)

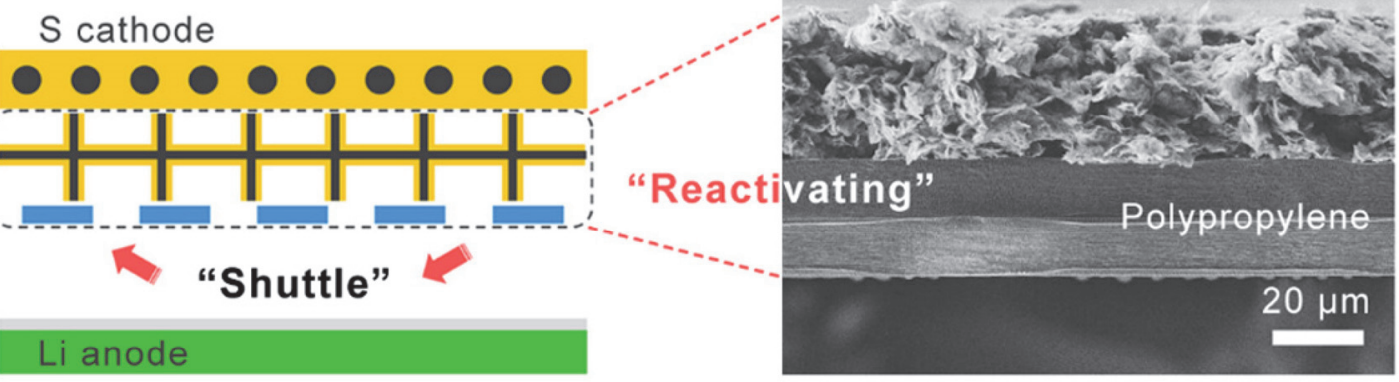

(d)
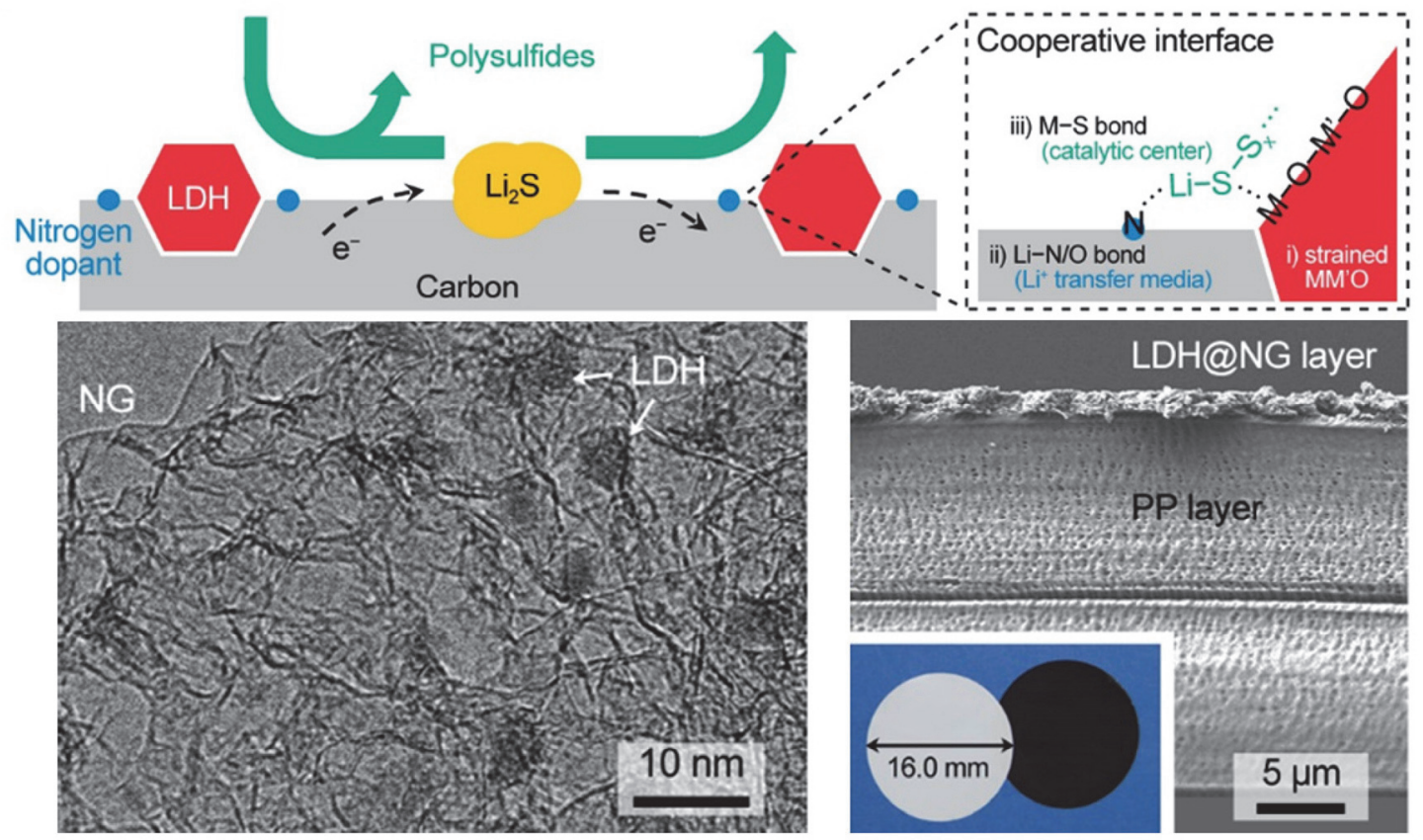

LDH@NG layer

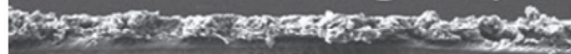

ayen
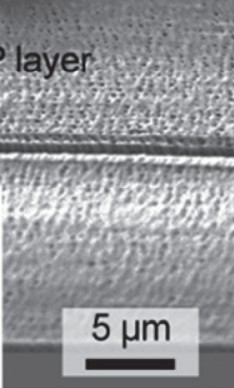

图 5 (a) 利用隔膜表面导电碳层修饰, 实现含硫组分回收利用的示意图 ${ }^{[128]}$; (b) 采用微孔碳和聚乙二醇形成隔复合膜修饰层, 实现多硫化物的吸 附和含硫组分再利用 ${ }^{[10]}$; (c) 利用多孔石墨烯骨架单元作为回收层, 起到活化惰性硫组分作用的示意图 ${ }^{[129]}$; (d) 利用氮掺杂介孔石墨烯与 $\mathrm{NiFe}$ 层 状双金属氢氧化物杂化材料修饰隔膜, 实现多硫化物双功能吸附及催化转化的示意图 ${ }^{[130]}$

Figure 5 (a) Scheme of Li-S battery with carbon-coated separator to recycle active materials ${ }^{[128]}$; (b) A microporous carbon/PEG-coated separator leading to adsorption and recycle of active materials ${ }^{[110]}$; (c) Scheme of porous graphene foam as recycle layer ${ }^{[129]}$; (d) Nitrogen doped mesoporous graphene and $\mathrm{NiFe}$ layered double hydroxides composite modified separator, achieving adsorption and rapid transition ${ }^{[130]}$ 
是包括锂硫电池在内的下一代高能量密度电池发展的 重要条件. 在锂硫电池体系中, 通过隔膜修饰一方面可 以抑制多硫化物到达负极表面, 影响负极界面固体电解 质层的稳定性; 另一方面, 通过调控负极表面的锂离子 沉积行为, 也有利于构建无枝晶生长, 具有高循环效率 的金属锂负极.

北京理工大学陈人杰研究组发展了一种利用多巴 胺修饰隔膜提升锂硫电池负极稳定性的策略. 针对采用 普通隔膜情况下枝晶生长破坏固体电解质层并导致电 池失效的问题, 利用原位聚合的多巴胺层对隔膜进行双 面修饰抑制枝晶的生长. 首先, 多巴胺在隔膜表面的聚 合使隔膜更加致密，一定程度上阻碍了多硫化物的透过 及其对固体电解质层的影响; 其次, 多巴胺与负极表面 接触可形成稳定的固体电解质层, 并在充放电过程中抑 制枝晶的生长; 另外, 多巴胺负载带来的较高电解液浸 润性也使锂离子浓度在负极表面的分布更均匀, 有利于 金属锂的均匀沉积. 对 1000 个循环后负极表面形貌的 扫描电子显微镜分析显示: 采用多巴胺修饰隔膜的负极 表面致密光滑, 未见明显枝晶产生; 而采用常规隔膜的 电池负极表面产生了大量枝晶突起结构. 利用多巴胺修

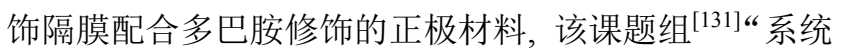
化” 地实现了高性能锂硫电池的制备, 在 $2 \mathrm{C}$ 的充放电 电流密度下, 维持了 3000 个充放电循环, 且单圈衰减率 在 $0.018 \%$ 以下. Kim 等 ${ }^{[132]}$ 也通过聚多巴胺修饰隔膜负 极一侧的方法, 改善了负极隔膜界面与金属锂负极的亲 和性, 提高了润湿性能. 另一方面, 聚多巴胺修饰层的 引入有效平衡了金属锂负极表面的锂离子浓度场, 实现 了锂硫电池中隔膜对负极枝晶生长的抑制.

针对负极表面锂离子和电子的分布不均匀性导致 锂离子的不均匀沉积这一现象. 本研究团队 ${ }^{[133]}$ 采用具 有较多极性基团的玻璃纤维作为隔膜修饰层, 实现了锂 离子在负极表面的均匀分布, 抑制了枝晶的生长, 获得 了高安全性的锂金属负极. 对普通的负极铜箔集流体来 说, 其表面突起部位易在潜力嵌锂过程中吸附大量锂离 子, 导致锂枝晶的生长. 且枝晶尖端具有更强的吸附锂 离子能力, 该正反馈效应将导致枝晶的持续生长. 在负 极一侧增加带有大量极性基团的玻璃纤维膜时, 玻璃纤 维对锂离子的吸附能力强于铜箔集流体, 从而能够引导 锂离子在负极表面的均匀沉积, 抑制了枝晶生长, 进而 获得了具有高安全性和长循环寿命的锂金属负极.

通过隔膜的修饰手段, 这些工作示范了一类高效解 决金属锂负极枝晶生长问题的思路, 对提升锂硫电池的 安全性, 能量效率和循环稳定性均有极大帮助. 这类研 究思路对下一代金属锂电池, 以及其他的金属负极电池 如镁金属电池、锌金属电池等均具有参考价值.

\section{4 总结与展望}

通过引入多功能隔膜系统, 可使锂硫电池在库伦效 率、比容量及循环稳定性等方面获得巨大提升. 通过利 用静电排斥、空间位阻及吸附等效应，引入具有多硫化 物阻挡作用的功能层, 多功能隔膜可以有效抑制锂硫电 池中多硫化物跨膜扩散导致的 “穿梭效应” 副反应，并 改善该副反应带来的包括低库伦效率、快速容量衰减等 一系列问题. 通过改变隔膜表面润湿性能及引入导电碳 层等手段，可以有效实现降低正极界面电阻、活性硫材 料回收等功能, 从而获得更高的正极硫利用率、循环稳 定性及更佳的倍率性能. 通过隔膜负极一侧改善隔膜负 极接触性能, 实现锂离子浓度场的均匀分布, 则可以利 用多功能隔膜的修饰有效稳定金属锂负极固体电解液 界面，抑制枝晶的生长，获得更安全的锂金属负极.

尽管锂硫电池中的多功能隔膜已取得巨大进展，其 后续研究及实用化进程仍存在巨大的发展空间. 首先, 针对抑制锂硫电池中多硫化物的扩散，进一步结合包括 静电排斥、空间位阻以及吸附等作用，一方面实现更高 效的多硫化物阻隔作用, 另一方面仍需着力提升锂离子 的透过能力, 提升锂硫电池的倍率性能. 其次, 在正极 一侧, 更好地结合导电层对正极界面反应的促进作用, 通过对多硫化物的吸附和电化学催化转化有效实现含 硫组分的回收，避免惰性沉淀的生成仍具有较大空间. 第三，针对金属锂负极界面稳定性问题，进一步深入理 解界面浸润性能、锂离子分布以及隔膜材料吸附锂离子 的能力对金属锂负极表面枝晶的生长及库伦效率的影 响, 将有助于面向改善负极性能的隔膜的概念设计.

在实用化方面, 通过对隔膜的多功能化, 可以在不 改变电池制程的前提下有效提升电化学性能，存在巨大 的应用潜能，但仍需在几个方面进一步改善多功能隔膜 结构及性能. 首先, 为保持锂硫电池高能量密度的性能 优势及特点, 在多功能隔膜的构建过程中需进一步降低 非活性材料的负载量, 以期在实现功能的同时降低对整 体能量密度的影响. 其次, 多功能隔膜的大规模应用有 赖于其大规模批量制备, 在维持多功能隔膜性能的同时 发展直接涂覆等方法将有利于实现隔膜的大面积制备. 第三，除了多功能隔膜的概念化验证，其在软包电池等 电池系统内的长期耐久性, 对电化学性能影响, 服役过 程中的结构变化等仍有待考察.

近年来，伴随着新材料的引入和更深入的机理理 解, 锂硫电池的性能发生了一系列飞跃. 其中, 针对锂 硫电池独特的反应特性, 多功能隔膜系统有效提升了电 池在库伦效率、比容量及稳定性等方面的性能. 随着对 多功能隔膜的更深入研究, 这一概念在锂硫电池中的性 能体现及大规模实用化仍存在辽阔的前景. 这一多功能 隔膜概念在其它多电子转化电化学储能体系如锂空电 池、锌空电池等中也具有重要借鉴意义. 

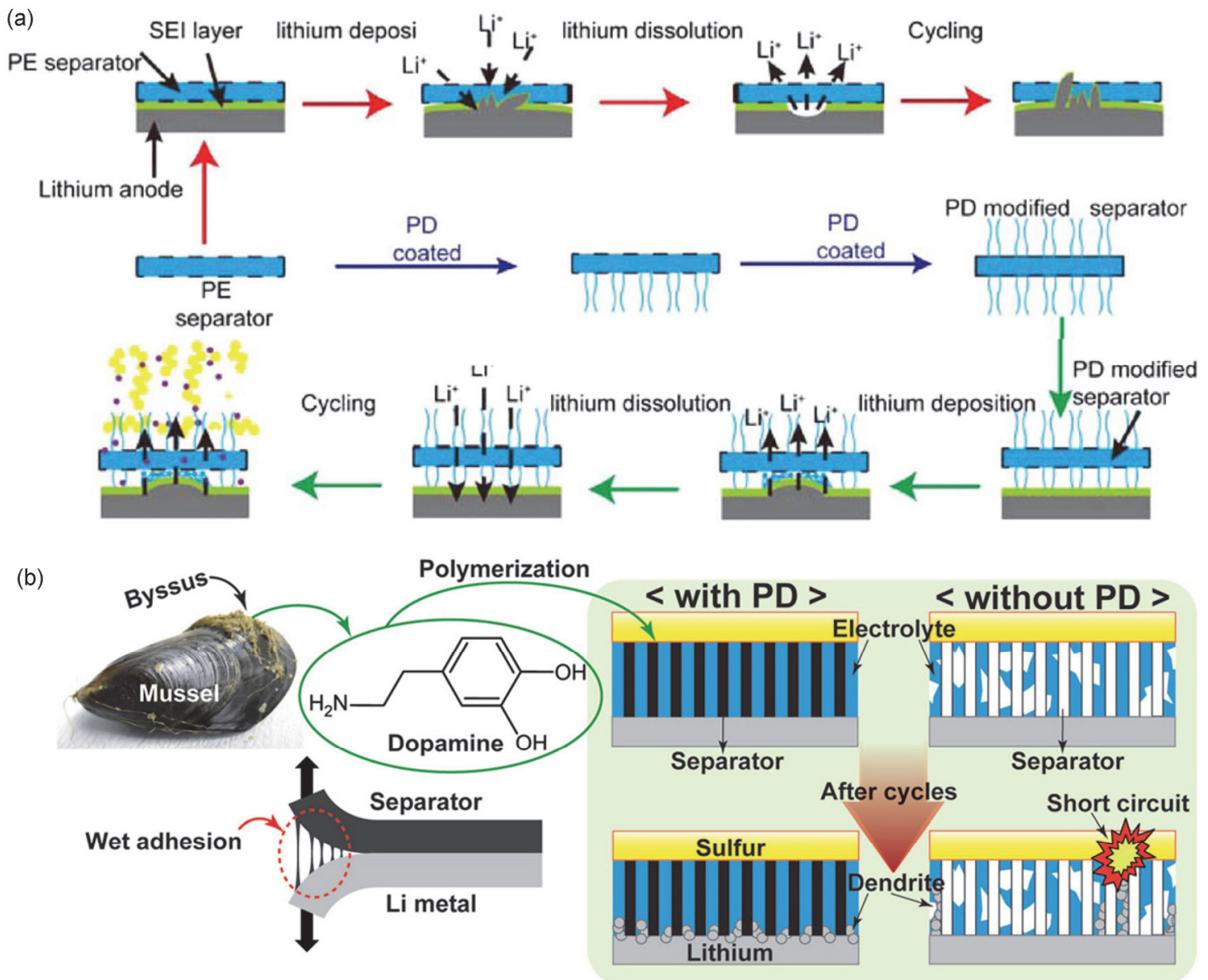

(c)

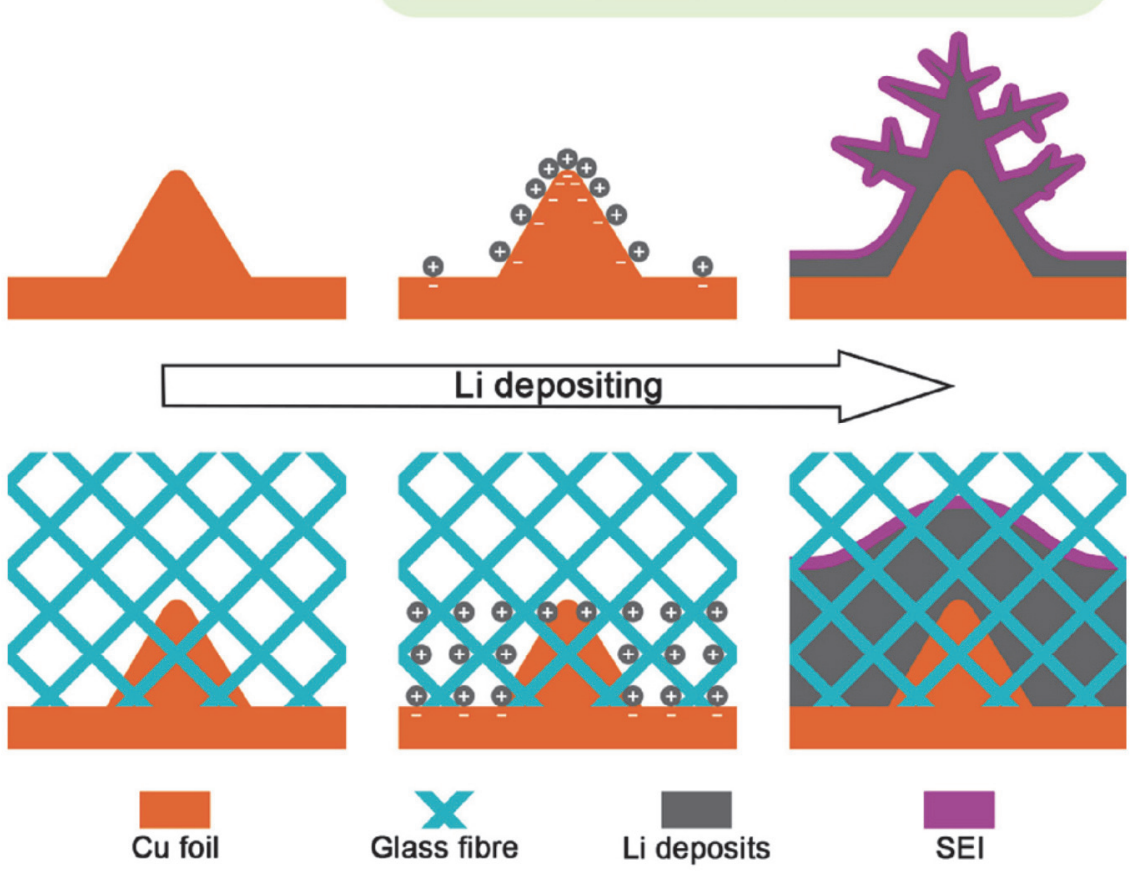

图 6 (a)利用多巴胺修饰 “系统化” 抑制负极枝晶生长的示意图 ${ }^{[131]}$; (b) 利用多巴胺修饰的隔膜改善与金属锂负极接触, 抑制枝晶生长的示意 图 ${ }^{[132]}$; (c)利用玻璃纤维诱导锂离子形成均匀浓度场, 抑制枝晶生长的示意图 ${ }^{[133]}$

Figure 6 (a) Scheme of biocell-inspired polydopamine as coating agent leading to "systematic effects" to impede growth of lithium dendrite ${ }^{[131]}$; (b) Scheme of polydopamine modified separator to impede growth of lithium dendrites ${ }^{[132]}$; (c) Scheme of nano fiber induced even concentration of lithium ion to retard the formation of Li dendrites in a working Li metal cell ${ }^{[133]}$ 


\section{作者简介}

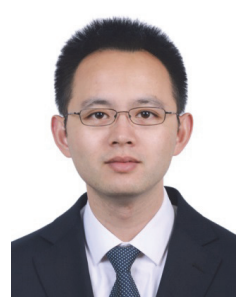

黄佳琦, 男, 博士, 特别研究员, 主要从事隔膜、电解质 与能源材料相关领域的研究.

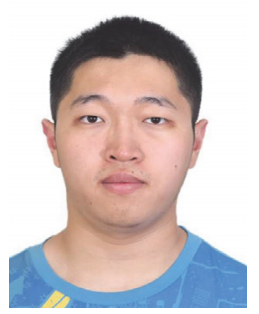

孙漟智, 男, 在读本科生, 主要从事高性能锂硫电池中离 子选择性隔膜制备与性能研究.

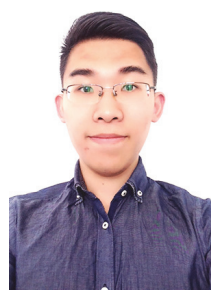

王云飞, 男, 在读博士生, 主要从事电化学能源相关材料 的研究.

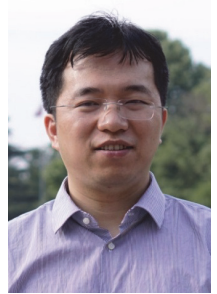

张强, 男, 博士, 万人计划青年拔尖人才, 国家优秀青年 基金获得者. 主要从事能源材料与能源化学工程相关领域的 研究.

\section{References}

[1] Armand, M.; Tarascon, J. M. Nature 2008, 451, 652.

[2] Liu, C.; Li, F.; Ma, L. P.; Cheng, H. M. Adv. Mater. 2010, 22, E28.

[3] Goodenough, J. B.; Kim, Y. Chem. Mater. 2010, 22, 587.

[4] Cheng, F.; Chen, J. Chem. Soc. Rev. 2012, 41, 2172.

[5] Manthiram, A.; Chung, S. H.; Zu, C. Adv. Mater. 2015, 27, 1980.

[6] Yin, Y. X.; Xin, S.; Guo, Y. G.; Wan, L. J. Angew. Chem., Int. Ed. 2013, 52, 13186

[7] Yin, Y. X.; Yao, H. R.; Guo, Y. G. Chin. Phys. B 2016, 25, 018801.

[8] Borchardt, L.; Oschatz, M.; Kaskel, S. Chem. Eur. J. 2016, 22, 7324.

[9] Gu, X. X.; Zhang, S. Q.; Hou, Y. L. Chin. J. Chem. 2016, 34, 11.

[10] Zhang, Q.; Cheng, X. B.; Huang, J. Q.; Peng, H. J.; Wei, F. New
Carbon Mater. 2014, 29, 241.

[11] Xu, G. Y.; Ding, B.; Pan, J.; Nie, P.; Shen, L. F.; Zhang, X. G. J. Mater. Chem. A 2014, 2, 12662.

[12] Lin, Z.; Liang, C. D. J. Mater. Chem. A 2015, 3, 936.

[13] Kang, W.; Deng, N.; Ju, J.; Li, Q.; Wu, D.; Ma, X.; Li, L.; Naebe, M.; Cheng, B. Nanoscale 2016, 8, 16541.

[14] Seh, Z. W.; Sun, Y.; Zhang, Q.; Cui, Y. Chem. Soc. Rev. 2016, 45, 5605.

[15] Wang, J. L.; Yang, J.; Xie, J. Y.; Xu, N. X. Adv. Mater. 2002, 14, 963.

[16] Ji, X. L.; Lee, K. T.; Nazar, L. F. Nat. Mater. 2009, 8, 500.

[17] Evers, S.; Nazar, L. F. Acc. Chem. Res. 2013, 46, 1135.

[18] Li, Z.; Huang, Y.; Yuan, L.; Hao, Z.; Huang, Y. Carbon 2015, 92, 41.

[19] Yang, Y.; Zheng, G.; Cui, Y. Chem. Soc. Rev. 2013, 42, 3018.

[20] Wang, J. G.; Xie, K.; Wei, B. Nano Energy 2015, 15, 413.

[21] Wu, S.; Ge, R.; Lu, M.; Xu, R.; Zhang, Z. Nano Energy 2015, 15, 379.

[22] Imtiaz, S.; Zhang, J.; Zafar, Z. A.; Ji, S.; Huang, T.; Anderson, J. A.; Zhang, Z.; Huang, Y. Sci. China Mater. 2016, 59, 389.

[23] Yuan, S. Y.; Guo, Z. Y.; Wang, L. N.; Hu, S.; Wang, Y. G.; Xia, Y. Y. Adv. Sci. 2015, 2, 1500071.

[24] Tang, C.; Zhang, Q.; Zhao, M. Q.; Huang, J. Q.; Cheng, X. B.; Tian, G. L.; Peng, H. J.; Wei, F. Adv. Mater. 2014, 26, 6100

[25] Song, J.; Xu, T.; Gordin, M. L.; Zhu, P.; Lv, D.; Jiang, Y. B.; Chen, Y.; Duan, Y.; Wang, D. Adv. Funct. Mater. 2014, 24, 1243.

[26] Peng, H. J.; Hou, T. Z.; Zhang, Q.; Huang, J. Q.; Cheng, X. B.; Guo, M. Q.; Yuan, Z.; He, L. Y.; Wei, F. Adv. Mater. Interfaces 2014, 1, 1400227.

[27] Tao, X.; Wang, J.; Liu, C.; Wang, H.; Yao, H.; Zheng, G.; Seh, Z. W.; Cai, Q.; Li, W.; Zhou, G.; Zu, C.; Cui, Y. Nat. Commun. 2016, 7, 11203.

[28] Yuan, Z.; Peng, H. J.; Hou, T. Z.; Huang, J. Q.; Chen, C. M.; Wang, D. W.; Cheng, X. B.; Wei, F.; Zhang, Q. Nano Lett. 2016, 16, 519.

[29] Zhang, J. T.; Hu, H.; Li, Z.; Lou, X. W. Angew. Chem. Int. Ed. 2016, 55,3982 .

[30] Wang, J. L.; He, Y. S.; Yang, J. Adv. Mater. 2015, 27, 569

[31] Wei, Y.; Tao, Y.; Kong, Z.; Liu, L.; Wang, J.; Qiao, W.; Ling, L.; Long, D. Energy Storage Mater. 2016, 5, 171.

[32] Liang, J.; Sun, Z. H.; Li, F.; Cheng, H. M. Energy Storage Mater. 2016, 2,76

[33] Lv, W.; Li, Z. J.; Deng, Y. Q.; Yang, Q. H.; Kang, F. Y. Energy Storage Mater. 2016, 2, 107.

[34] Yu, M.; Li, R.; Wu, M.; Shi, G. Energy Storage Mater. 2015, 1, 51.

[35] Yuan, Z.; Peng, H. J.; Huang, J. Q.; Liu, X. Y.; Wang, D. W.; Cheng, X. B.; Zhang, Q. Adv. Funct. Mater. 2014, 24, 6105.

[36] Zhao, Q.; Hu, X. F.; Zhang, K.; Zhang, N.; Hu, Y. X.; Chen, J. Nano Lett. 2015, 15, 721.

[37] Zhang, C.; Yang, Q. H. Sci. China-Mater. 2015, 58, 349.

[38] Cheng, X. B.; Zhang, R.; Zhao, C. Z.; Wei, F.; Zhang, J. G.; Zhang, Q. Adv. Sci. 2016, 3, 1500213.

[39] Jin, Z. Q.; Xie, K.; Hong, X. B. Acta Chim. Sinica 2014, 72, 11. (金 朝庆, 谢凯, 洪晓斌, 化学学报, 2014, 72, 11.)

[40] Cao, R. G.; Xu, W.; Lv, D. P.; Xiao, J.; Zhang, J. G. Adv. Energy Mater. 2015, 5, 1402273.

[41] Cheng, X. B.; Peng, H. J.; Huang, J. Q.; Wei, F.; Zhang, Q. Small 2014, 10, 4257.

[42] Cheng, X. B.; Peng, H. J.; Huang, J. Q.; Zhang, R.; Zhao, C. Z.; Zhang, Q. ACS Nano 2015, 9, 6373 .

[43] Yang, C. P.; Yin, Y. X.; Zhang, S. F.; Li, N. W.; Guo, Y. G. Nat. Commun. 2015, 6, 8058.

[44] Zhang, R.; Cheng, X. B.; Zhao, C. Z.; Peng, H. J.; Shi, J. L.; Huang, J. Q.; Wang, J. F.; Wei, F.; Zhang, Q. Adv. Mater. 2016, 28, 2155.

[45] Sun, Y.; Zheng, G.; Seh, Z. W.; Liu, N.; Wang, S.; Sun, J.; Lee, H. R.; Cui, Y. Chem 2016, 1, 287.

[46] Suo, L.; Hu, Y. S.; Li, H.; Armand, M.; Chen, L. Nat. Commun. 2013, 4, 1481.

[47] Zhao, C. Z.; Cheng, X. B.; Zhang, R.; Peng, H. J.; Huang, J. Q.; Ran, R.; Huang, Z. H.; Wei, F.; Zhang, Q. Energy Storage Mater. 2016, 3, 77.

[48] Yan, C.; Cheng, X.-B.; Zhao, C.-Z.; Huang, J.-Q.; Yang, S.-T.; Zhang, Q. J. Power Sources 2016, 327, 212.

[49] Huang, J. Q.; Zhang, Q.; Wei, F. Energy Storage Mater. 2015, 1, 127.

[50] Arora, P.; Zhang, Z. M. Chem. Rev. 2004, 104, 4419.

[51] Kang, W. M.; Ma, X. M.; Zhao, Y. X.; Zhao, H. H.; Cheng, B. W.; 
Liu, Y. B. Acta Polym. Sin. 2015, 1258. (康卫民，马晓敏，赵义侠， 赵卉卉, 程博闻, 刘延波, 高分子学报, 2015, 1258.)

[52] Mikhaylik, Y. V.; Akridge, J. R. J. Electrochem. Soc. 2004, 151, A1969.

[53] Jin, Z. Q.; Xie, K.; Hong, X. B.; Hu, Z. Q.; Liu, X. J. Power Sources 2012, 218, 163 .

[54] Yu, X.; Joseph, J.; Manthiram, A. J. Mater. Chem. A 2015, 3, 15683.

[55] Huang, J. Q.; Zhang, Q.; Peng, H. J.; Liu, X. Y.; Qian, W. Z.; Wei, F. Energy Environ. Sci. 2014, 7, 347.

[56] Xu, W. T.; Peng, H. J.; Huang, J. Q.; Zhao, C. Z.; Cheng, X. B.; Zhang, Q. ChemSusChem 2015, 8, 2892.

[57] Bauer, I.; Thieme, S.; Bruckner, J.; Althues, H.; Kaskel, S. J. Power Sources 2014, 251, 417.

[58] Yu, X.; Manthiram, A. Adv. Energy Mater. 2015, 5, 1500350.

[59] Bauer, I.; Kohl, M.; Althues, H.; Kaskel, S. Chem. Commun. 2014, $50,3208$.

[60] Liu, X.; Shan, Z.; Zhu, K.; Du, J.; Tang, Q.; Tian, J. J. Power Sources 2015, 274, 85.

[61] Zhuang, T. Z.; Huang, J. Q.; Peng, H. J.; He, L. Y.; Cheng, X. B.; Chen, C. M.; Zhang, Q. Small 2016, 12, 381.

[62] Hao, Z. X.; Yuan, L. X.; Li, Z.; Liu, J.; Xiang, J. W.; Wu, C.; Zeng, R.; Huang, Y. H. Electrochim. Acta 2016, 200, 197.

[63] Cai, W. L.; Li, G. R.; He, F.; Jin, L. M.; Liu, B. H.; Li, Z. P. J. Power Sources 2015, 283, 524.

[64] Jin, Z. Q.; Xie, K.; Hong, X. B. RSC Adv. 2013, 3, 8889.

[65] Gu, M.; Lee, J.; Kim, Y.; Kim, J. S.; Jang, B. Y.; Lee, K. T.; Kim, B. S. $R S C A d v . \mathbf{2 0 1 4}, 4,46940$.

[66] Conder, J.; Forner-Cuenca, A.; Gubler, E. M.; Gubler, L.; Novák, P.; Trabesinger, S. ACS Appl. Mater. Interfaces 2016, 8, 18822.

[67] Conder, J.; Urbonaite, S.; Streich, D.; Novák, P.; Gubler, L. RSC Adv. 2015, 5, 79654.

[68] Zeng, F.; Jin, Z.; Yuan, K.; Liu, S.; Cheng, X.; Wang, A.; Wang, W.; Yang, Y. S. J. Mater. Chem. A 2016, 4, 12319.

[69] Ahn, W.; Lim, S. N.; Lee, D. U.; Kim, K. B.; Chen, Z. W.; Yeon, S. H. J. Mater. Chem. A 2015, 3, 9461.

[70] Yim, T.; Han, S. H.; Park, N. H.; Park, M. S.; Lee, J. H.; Shin, J.; Choi, J. W.; Jung, Y.; Jo, Y. N.; Yu, J. S.; Kim, K. J. Adv. Funct. Mater. 2016, 26, 7817.

[71] Joshi, R. K.; Carbone, P.; Wang, F. C.; Kravets, V. G.; Su, Y.; Grigorieva, I. V.; Wu, H. A.; Geim, A. K.; Nair, R. R. Science 2014, $343,752$.

[72] Nair, R. R.; Wu, H. A.; Jayaram, P. N.; Grigorieva, I. V.; Geim, A. K. Science 2012, 335, 442.

[73] Huang, J. Q.; Zhuang, T. Z.; Zhang, Q.; Peng, H. J.; Chen, C. M.; Wei, F. ACS Nano 2015, 9, 3002.

[74] Lin, W.; Chen, Y.; Li, P.; He, J.; Zhao, Y.; Wang, Z.; Liu, J.; Qi, F.; Zheng, B.; Zhou, J.; Xu, C.; Fu, F. J. Electrochem. Soc. 2015, 162, A1624.

[75] Wu, F.; Qian, J.; Chen, R.; Ye, Y.; Sun, Z.; Xing, Y.; Li, L. J. Mater. Chem. A 2016, 4, 17033.

[76] Sun, J.; Sun, Y.; Pasta, M.; Zhou, G.; Li, Y.; Liu, W.; Xiong, F.; Cui, Y. Adv. Mater. 2016, 28, 9797.

[77] Zhou, G. M.; Pei, S. F.; Li, L.; Wang, D. W.; Wang, S. G.; Huang, K.; Yin, L. C.; Li, F.; Cheng, H. M. Adv. Mater. 2014, 26, 625.

[78] Bai, S.; Liu, X.; Zhu, K.; Wu, S.; Zhou, H. Nature Energy 2016, 1, 16094.

[79] Bai, S.; Zhu, K.; Wu, S.; Wang, Y.; Yi, J.; Ishida, M.; Zhou, H. J. Mater. Chem. A 2016, 4, 16812.

[80] Li, C. Y.; Ward, A. L.; Doris, S. E.; Pascal, T. A.; Prendergast, D.; Helms, B. A. Nano Lett. 2015, 15, 5724.

[81] Li, W.; Hicks-Garner, J.; Wang, J.; Liu, J.; Gross, A. F.; Sherman, E.; Graetz, J.; Vajo, J. J.; Liu, P. Chem. Mater. 2014, 26, 3403.

[82] Yu, X. W.; Bi, Z. H.; Zhao, F.; Manthiram, A. ACS Appl. Mater. Interfaces 2015, 7, 16625 .

[83] Zhang, Z. Y.; Lai, Y. Q.; Zhang, Z. A.; Zhang, K.; Li, J. E. Electrochim. Acta 2014, 129, 55.

[84] Chung, S. H.; Han, P.; Singhal, R.; Kalra, V.; Manthiram, A. Adv. Energy Mater. 2015, 5, 1500738.

[85] Wei, H.; Ma, J.; Li, B. A.; Zuo, Y. X.; Xia, D. G. ACS Appl. Mater. Interfaces 2014, 6, 20276.

[86] Wang, Z.; Zhang, J.; Yang, Y.; Yue, X.; Hao, X.; Sun, W.; Rooney, D.; Sun, K. J. Power Sources 2016, 329, 305.

[87] Liu, N.; Huang, B.; Wang, W.; Shao, H.; Li, C.; Zhang, H.; Wang, A.; Yuan, K.; Huang, Y. ACS Appl. Mater. Interfaces 2016, 8, 16101.

[88] Shao, H.; Huang, B.; Liu, N.; Wang, W.; Zhang, H.; Wang, A.; Wang, F.; Huang, Y. J. Mater. Chem. A 2016, 4, 16627.
[89] Lapornik, V.; Tusar, N. N.; Ristic, A.; Chellappan, R. K.; Foix, D.; Dedryvere, R.; Gaberscek, M.; Dominko, R. J. Power Sources 2015, 274, 1239.

[90] Nair, J. R.; Bella, F.; Angulakshmi, N.; Stephan, A. M.; Gerbaldi, C. Energy Storage Mater. 2016, 3, 69.

[91] Qian, X.; Jin, L.; Zhao, D.; Yang, X.; Wang, S.; Shen, X.; Rao, D.; Yao, S.; Zhou, Y.; Xi, X. Electrochim. Acta 2016, 192, 346.

[92] Wang, H. Q.; Zhang, W. C.; Liu, H. K.; Guo, Z. P. Angew. Chem., Int. Ed. 2016, 55, 3992.

[93] Zhang, Y.; Miao, L.; Ning, J.; Xiao, Z.; Hao, L.; Wang, B.; Zhi, L. 2 D Mater. 2015, 2, 024013.

[94] Cheng, X.; Wang, W.; Wang, A.; Yuan, K.; Jin, Z.; Yang, Y.; Zhao, X. RSC Adv. 2016, 6, 89972 .

[95] Hou, T. Z.; Peng, H. J.; Huang, J. Q.; Zhang, Q.; Li, B. 2D Mater. 2015, 2, 014011 .

[96] Chang, C. H.; Chung, S. H.; Manthiram, A. J. Mater. Chem. A 2015, 3,18829 .

[97] Zhu, J.; Chen, C.; Lu, Y.; Zang, J.; Jiang, M.; Kim, D.; Zhang, X. Carbon 2016, 101, 272.

[98] Hou, T. Z.; Chen, X.; Peng, H. J.; Huang, J. Q.; Li, B. Q.; Zhang, Q.; Li, B. Small 2016, 12, 3283.

[99] Fan, C. Y.; Yuan, H. Y.; Li, H. H.; Wang, H. F.; Li, W. L.; Sun, H. Z.; Wu, X. L.; Zhang, J. P. ACS Appl. Mater. Interfaces 2016, 8, 16108.

[100] Song, J. X.; Gordin, M. L.; Xu, T.; Chen, S. R.; Yu, Z. X.; Sohn, H.; Lu, J.; Ren, Y.; Duan, Y. H.; Wang, D. H. Angew. Chem., Int. Ed. 2015, 54, 4325 .

[101] Peng, H. J.; Zhang, Q. Angew. Chem., Int. Ed. 2015, 54, 11018.

[102] Zhou, X.; Liao, Q.; Tang, J.; Bai, T.; Chen, F.; Yang, J. J. Electroanal. Chem. 2016, 768, 55 .

[103] Balach, J.; Jaumann, T.; Klose, M.; Oswald, S.; Eckert, J.; Giebeler, L. J. Power Sources 2016, 303, 317.

[104] Lin, C.; Zhang, W.; Wang, L.; Wang, Z.; Zhao, W.; Duan, W.; Zhao, Z.; Liu, B.; Jin, J. J. Mater. Chem. A 2016, 4, 5993.

[105] Peng, H. J.; Zhang, G.; Chen, X.; Zhang, Z. W.; Xu, W. T.; Huang, J. Q.; Zhang, Q. Angew. Chem., Int. Ed. 2016, 55, 12990.

[106] Xiao, Z. B.; Yang, Z.; Wang, L.; Nie, H. G.; Zhong, M. E.; Lai, Q. Q.; Xu, X. J.; Zhang, L. J.; Huang, S. M. Adv. Mater. 2015, 27, 2891.

[107] Song, J.; Su, D.; Xie, X.; Guo, X.; Bao, W.; Shao, G.; Wang, G. ACS Appl. Mater. Interfaces 2016, 8, 29427.

[108] Chung, S. H.; Chang, C. H.; Manthiram, A. Small 2016, 12, 939.

[109] Chung, S. H.; Manthiram, A. J. Phys. Chem. Lett. 2014, 5, 1978.

[110] Chung, S. H.; Manthiram, A. Adv. Mater. 2014, 26, 7352.

[111] Chung, S. H.; Manthiram, A. Adv. Funct. Mater. 2014, 24, 5299.

[112] Zhang, Z.; Lai, Y.; Zhang, Z.; Li, J. Solid State Ionics 2015, 278, 166.

[113] Wang, Q.; Wen, Z.; Yang, J.; Jin, J.; Huang, X.; Wu, X.; Han, J. J. Power Sources 2016, 306, 347.

[114] Zhu, J.; Ge, Y.; Kim, D.; Lu, Y.; Chen, C.; Jiang, M.; Zhang, X. Nano Energy 2016, 20, 176.

[115] Zhao, D.; Qian, X.; Jin, L.; Yang, X.; Wang, S.; Shen, X.; Yao, S.; Rao, D.; Zhou, Y.; Xi, X. RSC Adv. 2016, 6, 13680.

[116] Balach, J.; Jaumann, T.; Klose, M.; Oswald, S.; Eckert, J.; Giebeler, L. Adv. Funct. Mater. 2015, 25, 5285.

[117] Zhang, Z.; Wang, G. C.; Lai, Y. Q.; Li, J.; Zhang, Z. Y.; Chen, W. J. Power Sources 2015, 300, 157.

[118] Wang, G. C.; Lai, Y. Q.; Zhang, Z. A.; Li, J.; Zhang, Z. Y. J. Mater. Chem. A 2015, 3, 7139 .

[119] Luo, L.; Chung, S. H.; Manthiram, A. J. Mater. Chem. A 2016, 4 , 16805.

[120] Chen, Y. L.; Liu, N. Q.; Shao, H. Y.; Wang, W. K.; Gao, M. Y.; Li, C. M.; Zhang, H.; Wang, A. B.; Huang, Y. Q. J. Mater. Chem. A 2015 3,15235 .

[121] Zhou, G.; Li, L.; Wang, D. W.; Shan, X. Y.; Pei, S.; Li, F.; Cheng, H. M. Adv. Mater. 2015, 27, 641

[122] Wang, L.; Liu, J. Y.; Haller, S.; Wang, Y. G.; Xia, Y. Y. Chem. Commun. 2015, 51, 6996.

[123] Zhu, J.; Yanilmaz, M.; Fu, K.; Chen, C.; Lu, Y.; Ge, Y.; Kim, D.; Zhang, X. J. Membrane Sci. 2016, 504, 89.

[124] Li, Z.; Jiang, Q. Q.; Ma, Z. L.; Liu, Q. H.; Wu, Z. J.; Wang, S. Y. RSC Adv. 2015, 5, 79473.

[125] Li, G. C.; Jing, H. K.; Su, Z.; Lai, C.; Chen, L.; Yuan, C. C.; Li, H. H.; Liu, L. J. Mater. Chem. A 2015, 3, 11014.

[126] Zhang, Z.; Zhang, Z.; Li, J.; Lai, Y. J. Solid State Electr. 2015, 19 , 1709 .

[127] Ma, G.; Huang, F.; Wen, Z.; Wang, Q.; Hong, X.; Jin, J.; Wu, X. J. 
Mater. Chem. A 2016, 4, 16968.

[128] Yao, H.; Yan, K.; Li, W.; Zheng, G.; Kong, D.; Seh, Z. W.; Narasimhan, V. K.; Liang, Z.; Cui, Y. Energy Environ. Sci. 2014, 7, 3381.

[129] Peng, H. J.; Wang, D. W.; Huang, J. Q.; Cheng, X. B.; Yuan, Z.; Wei, F.; Zhang, Q. Adv. Sci. 2016, 3, 1500268.

[130] Peng, H. J.; Zhang, Z. W.; Huang, J. Q.; Zhang, G.; Xie, J.; Xu, W. T.; Shi, J. L.; Chen, X.; Cheng, X. B.; Zhang, Q. Adv. Mater. 2016, $28,9551$.
[131] Wu, F.; Ye, Y.; Chen, R.; Qian, J.; Zhao, T.; Li, L.; Li, W. Nano Lett. 2015, 15, 7431.

[132] Kim, J. S.; Hwang, T. H.; Kim, B. G.; Min, J.; Choi, J. W. $A d v$. Funct. Mater. 2014, 24, 5359 .

[133] Cheng, X. B.; Hou, T. Z.; Zhang, R.; Peng, H. J.; Zhao, C. Z.; Huang, J. Q.; Zhang, Q. Adv. Mater. 2016, 28, 2888.

(Zhao, X.) 